\title{
Evaluating the Bias of South China Sea Summer Monsoon Precipitation Associated with Fast Physical Processes Using a Climate Model Hindcast Approach $\mathscr{O}$
}

\author{
Wei-Ting Chen And ChIEn-Ming Wu \\ Department of Atmospheric Sciences, National Taiwan University, Taipei, Taiwan \\ HSI-YEN MA \\ Lawrence Livermore National Laboratory, Livermore, California
}

(Manuscript received 2 October 2018, in final form 4 March 2019)

\begin{abstract}
The present study aims to identify the precipitation bias associated with the interactions among fast physical processes in the Community Atmospheric Model, version 5 (CAM5), during the abrupt onset of the South China Sea (SCS) summer monsoon, a key precursor of the overall East Asia summer monsoon (EASM). The multiyear hindcast approach is utilized to obtain the well-constrained synoptic-scale horizontal circulation each year during the onset period from the years 1998 to 2012. In the pre-onset period, the ocean precipitation over the SCS is insufficiently suppressed in CAM5 hindcasts and thus weaker land-ocean precipitation contrasts. This is associated with the weaker and shallower convection simulated over the surrounding land, producing weaker local circulation within the SCS basin. In the post-onset period, rainfall of the organized convection over the Philippine coastal ocean is underestimated in the hindcasts, with overestimated upperlevel heating. These biases are further elaborated as the underrepresentation of the convection diurnal cycle and coastal convection systems, as well as the issue of precipitation sensitivity to environmental moisture during the SCS onset period. The biases identified in hindcasts are consistent with the general bias of the EASM in the climate simulation of CAM5. The current results highlight that the appropriate representation of land-ocean-convection interactions over coastal areas can potentially improve the simulation of seasonal transition over the monsoon regions.
\end{abstract}

\section{Introduction}

Regional monsoons affect the precipitation and atmospheric circulation where over two-thirds of the world's population resides (Zhou et al. 2016). Future climate projection of the regional monsoon variability is therefore potentially of great societal concern. However, the state-of-the-art global climate models (GCMs) encounter great challenges when simulating the monsoon systems, including their evolution and variability (e.g., Annamalai et al. 2007, 2017; Cook et al. 2012; Kitoh et al. 2013; Randall et al. 2007; Song and Zhou 2014a,b; Sperber et al. 2013; Wang et al. 2005; Zhou et al.

\footnotetext{
Supplemental information related to this paper is available at the Journals Online website: https://doi.org/10.1175/JCLI-D-180660.s1.
}

Corresponding author: Wei-Ting Chen, weitingc@ntu.edu.tw
2009, 2016), although progressive improvements have been made from phase 3 of the Coupled Model Intercomparison Project (CMIP3) to phase 5 (CMIP5) (Christensen et al. 2013).

Various coordinated efforts in the monsoon community have been undertaken for better understanding and improving global monsoon simulations and prediction [e.g., Global Monsoon Model Intercomparison Project (GMMIP); Zhou et al. 2016]. While all experiments are of the Atmospheric Model Intercomparison Project (AMIP) or CMIP type in the GMMIP and in most of the earlier studies listed above, it remains challenging for processlevel understanding of monsoon simulations, especially to better attribute simulated biases to particular dynamical or physical processes. As the monsoon systems involve the regionally distinct interactions between atmospheric circulation and rainfall (Sperber et al. 2013; Webster et al. 1998), the biases in monsoon-related precipitation and winds in the AMIP- or CMIP-type simulations are usually 
the results of the complex feedback among processes across different spatial and temporal scales.

The climate model hindcast approach (Phillips et al. 2004) or the transpose-AMIP approach (Williams et al. 2013) is useful for understanding climate model errors associated with fast physical processes (i.e., moist convection, diurnal cycle, local land-sea breezes, etc.) in the atmosphere, and facilitating model parameterization improvements. Initialized with the reanalysis (observation) data, the synoptic-scale circulation and atmospheric states remain close to the reanalysis (observations) in the first few days of the hindcasts, while the biases in precipitation and clouds are possibly the results of parameterization deficiencies (Ma et al. 2013, 2014, 2015; Xie et al. 2012) or a strong local interaction between the parameterized physics and dynamics (Williamson 2013). If the biases in the short-range hindcasts exhibit a good correspondence to the systematic biases in the long-term climate simulation, reducing the biases in the hindcast mode can likely improve the climate simulations. Previous studies (Ma et al. 2014, 2015; Xie et al. 2012) have shown that the annual and seasonal mean biases of precipitation and clouds present in the multiyear short-term hindcasts of the Community Atmospheric Model, version 5 (CAM5), and other GCMs share great resemblance to the systematic biases in their AMIP simulations. However, application of the multiyear hindcast approach to understand the precipitation biases specifically associated with monsoons or seasonal evolution has not been carried out.

In the present study, it will be the first time that the multiyear (15 years) short-range hindcast framework is applied to relate the systematic bias of monsoon precipitation to the interactions among fast physical processes. The CAM5 hindcasts during the onset of the South China Sea summer monsoon (SCSSM) will be analyzed. This is the region and period when the CAM5 AMIP simulation exhibits obvious bias in the monsoon intensity, onset, and duration, as we will show later in section 3a. The manuscript is organized as follows. The configuration of the hindcast experiments and the observational and reanalysis datasets to evaluate the simulations are described in section 2 . In section 3 , the general bias of Asian monsoon in CAM5 AMIP will be presented first and compared to the results of the multiyear hindcasts. Then the precipitation bias in the hindcasts during the pre-onset period and post-onset period of the SCSSM are analyzed. Section 4 discusses the details of the precipitation bias associated with the diurnal-cycle rainfall and sensitivity of precipitation to ambient moisture. The final conclusions are provided in section 5 .

\section{Datasets}

\section{a. Hindcast experiments}

We applied the short-range hindcast approach from the U.S. Department of Energy Cloud Associated Parameterizations Testbed (CAPT) following Ma et al. $(2013,2014,2015)$. The CAPT hindcasts analyzed in this study were carried out using the CAM5 (version cesm1_ 0_5) with finite-volume dynamical core, a horizontal resolution of $0.9^{\circ} \times 1.25^{\circ}$ (latitude by longitude), 30 vertical levels, prescribed SST, and the Community Land Model, version 4.0 (CLM4). The physics package pertinent to the hindcast simulations consist of the deep convection scheme (Zhang and McFarlane 1995; Neale et al. 2008), the double-moment microphysics scheme (Morrison and Gettelman 2008; Gettelman et al. 2010), the diagnostic cloud fraction (macrophysics) scheme (Park et al. 2014), the shallow convection scheme (Park and Bretherton 2009), the moist turbulence scheme (Bretherton and Park 2009), the Rapid Radiative Transfer Model for GCMs (RRTMG) (Iacono et al. 2008), and the modal aerosol model (Liu et al. 2012).

The 3-day-long hindcasts were initialized at 0000 UTC every day for the years 1998-2012, with prescribed NOAA Optimum Interpolation (OI) weekly SSTs and sea ice (Reynolds et al. 2002). Initial atmospheric state variables (horizontal velocities, temperature, specific humidity, and surface pressure) are from the European Centre for Medium-Range Weather Forecasts (ECMWF) interim reanalysis (ERA-Interim, hereinafter ERA-Int; Dee et al. 2011). The initialization procedure is described in Ma et al. (2015). Based on the results in Ma et al. $(2013,2014)$, the effects of spinup due to initializing the CAM5 model with a "foreign" (ECMWF) analysis would have impacts on the first $24 \mathrm{~h}$ (i.e., day-1 hindcast ensembles). Afterward the tropical precipitation in the hindcasts reaches a relative equilibrium state close to the AMIP simulation of CAM5. Therefore in this study we concatenated each hindcast from 24- to 48-h lead time to form the day-2 time series (48-72h for day 3) of the data stream from 1998 to 2012. We also performed a companion AMIP simulation for the same period with the same boundary conditions (NOAA OI SST and sea ice).

\section{b. Observation and reanalysis datasets}

Daily mean observed winds and humidity for the same period are taken from ERA-Int with a horizontal resolution of $0.75^{\circ} \times 0.75^{\circ}$. Daily mean precipitation estimates are taken from the Global Precipitation Climatology Project (GPCP) 1DD, version 1.2 (Huffman et al. 2001), and the Tropical Rainfall Measuring Mission (TRMM) 3B42, version 
7, dataset (Kummerow et al. 2000; Huffman et al. 2010) from 1998 to 2015. GPCP precipitation is based on microwave, infrared, and rain gauge observations (Huffman et al. 1997), with a horizontal resolution of $1^{\circ} \times 1^{\circ}$. TRMM 3B42 is the merged microwave, Precipitation Radar (PR), and infrared level-3 rainfall product at a horizontal resolution of $0.25^{\circ} \times 0.25^{\circ}$, with the calibration of rain gauge data on a monthly basis. We used two precipitation estimates here to provide the possible range of observational uncertainty. The model biases that are robust against both datasets will be the focus of subsequent discussion.

Vertical profiles of large-scale diabatic heating Q1 QR (apparent heat source minus radiative heating) (Yanai et al. 1973) are retrieved from TRMM PR based on the spectral latent heating (SLH) algorithm (Shige et al. 2004, 2007, 2008, 2009), with a horizontal resolution of $0.5^{\circ} \times 0.5^{\circ}$. We note that the PR can only detect precipitating particles (reflectivity $>17 \mathrm{dBZ}$ ), so the Q1 - QR estimated by the SLH algorithm is mainly associated with the deep modes and congestus modes, while the contribution from weakly precipitating shallow convection is underestimated as reported in Takayabu et al. (2010) and Tao et al. (2016). Shige et al. (2007) evaluated the TRMM SLH Q1 - QR heating profiles against the sounding-based analysis of diabatic heating for the 1998 South China Sea Monsoon Experiment (SCSMEX) derived by Johnson and Ciesielski (2002) over the northern SCS, the main focusing area of this study. The key features of the vertical profiles, particularly the level of maximum heating, agreed well with the sounding estimates. In the lower atmosphere (below $\sim 5 \mathrm{~km}$ ) the magnitude of TRMM SLH Q1 - QR plus QR from cloudresolving simulation is about $1 \mathrm{~K}$ higher than Q1 from sounding analysis, which is likely associated with sampling bias of PR (Shige et al. 2007). With a narrow swath width $(\sim 215 \mathrm{~km})$, the PR detects moderate to heavy rainfall more frequently when compared to the microwave imager, which may lead to underestimation of stratiform cooling in the lower atmosphere.

\section{Results}

\section{a. General bias of the Asian monsoon in CAM5 AMIP}

Figure 1a evaluates the overall monsoon domain and monsoon intensity over Asia in the CAM5 AMIP simulation from 1998 to 2012 against the precipitation estimates of GPCP and TRMM 3B42, following the global monsoon definition by Wang and Ding (2008), Wang et al. (2011), and Kim et al. (2011) based on the annual range of rainfall (see caption of Fig. 1 for details). Here we use May-September as summer and November-March as winter for Northern Hemisphere, and vice versa for Southern Hemisphere. The CAM5 AMIP captures the overall shape of the monsoon domain and intensity, but with obvious bias over specific regions. Over the Asian continent, the simulated monsoon domain and intensity agree fairly well with the two observations, except for underestimation over the central part of eastern China. However, over the coastal oceans of the Bay of Bengal (BoB) and the South China Sea (SCS), as well as in western North Pacific (WNP), the monsoon domain in CAM5 AMIP is smaller than either observational estimate, and within the simulated monsoon domain, the monsoon intensity is also weaker than both observations.

Figures $1 \mathrm{~b}$ and $1 \mathrm{c}$ show the diagnostic metrics for summer monsoon onset and duration adopted in Sperber et al. (2013) and Sperber and Annamalai (2014), which is based on the fractional accumulation of precipitation. The onset pentad at each grid (Fig. 1b) is defined as Julian pentad at which the accumulated rainfall exceeds $20 \%$ of the total annual rainfall of the grid. The monsoon duration (Fig. 1c) is defined by the number of pentads between the accumulated rainfall fraction of $20 \%$ and $80 \%$. We noted that Sperber et al. (2013) evaluated the Asian monsoon performance in CMIP3 and CMIP5 models using these metrics, and the CCSM4 (the coupled version of CAM4) is actually one of the top-performing models. Here we are trying to identify specific regions where obvious biases still exist in CAM5 AMIP. Over the oceanic regions where the monsoon domain is missing or the monsoon intensity is underestimated (over the BoB, EA, SCS, and WNP), the CAM5 AMIP shows earlier onset by four pentads or more, with longer duration of summer monsoon than both observations (note that over the white areas in Fig. 1c the duration is longer than 33 pentads, i.e., $>5$ months) This indicates that the simulated summertime precipitation intensity is too weak, such that it takes a longer time span to reach the $80 \%$ rainfall fraction. Overall, the Asian summer monsoon characteristics are well simulated by the CAM5 AMIP, but over specific ocean regions the monsoon is "too early, too long, and too weak."

Figure 2a shows the bias of monsoon intensity in CAM5 AMIP simulation relative to TRMM 3B42 within the observed monsoon domain (green contour). The model significantly underestimates the intensity over the SCS, the BoB, and the Arabian Sea. The negative bias of monsoon intensity is larger over the windward coastal ocean under the summertime prevailing low-level southwesterly winds (i.e., the eastern part of the ocean basins), and the magnitude decreases from 
GPCP 1998-2012

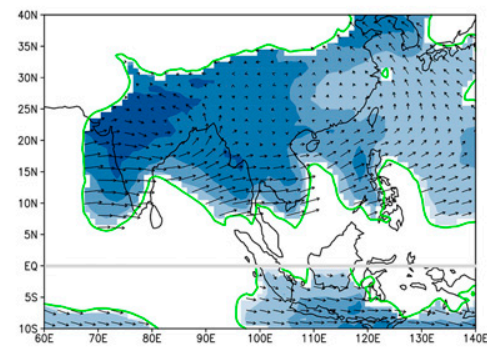

(b)

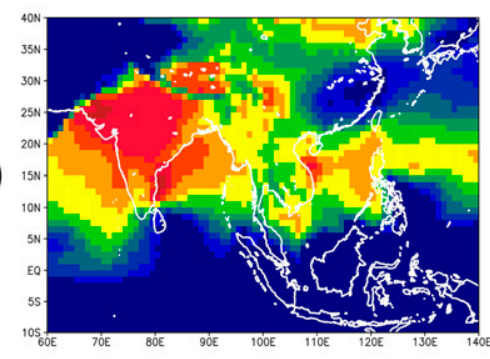

(c)

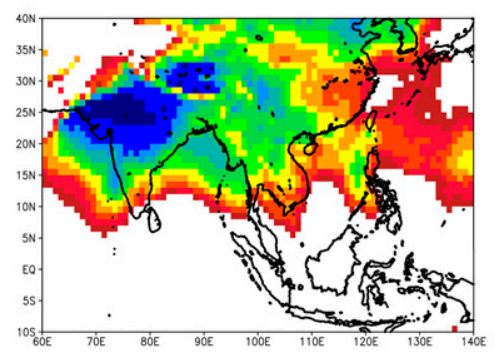

TRMM 1998-2012
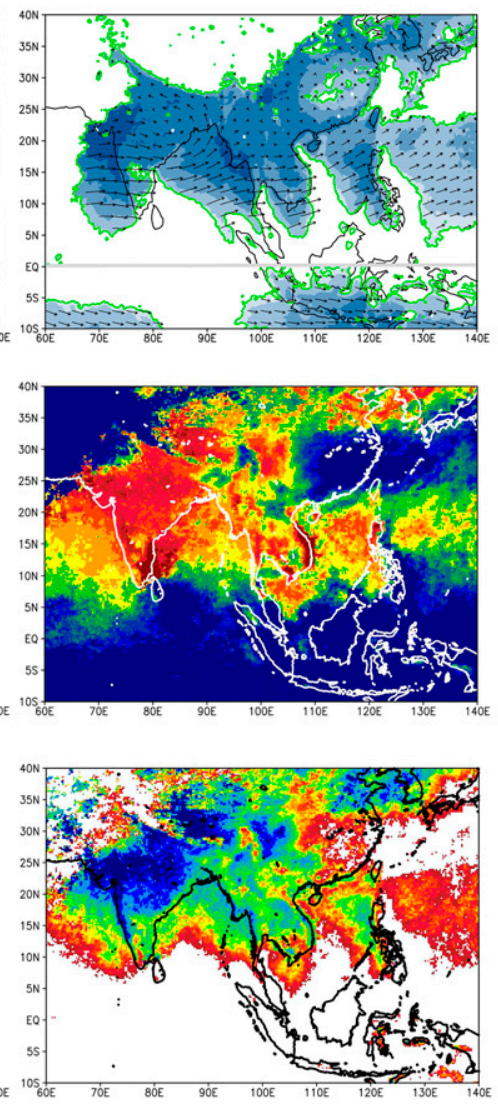

CAM5 AMIP 1998-2012

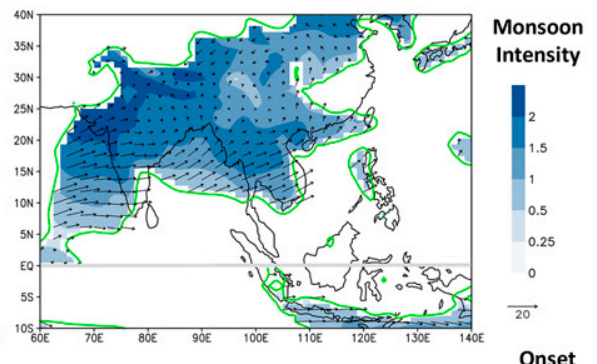

Onset

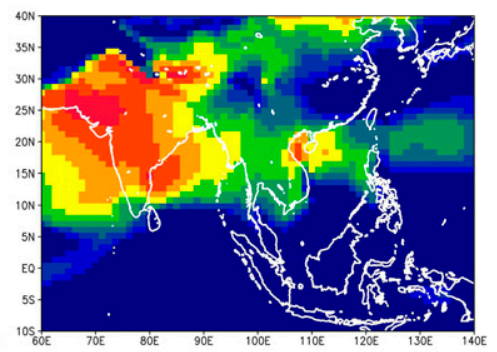

Duration

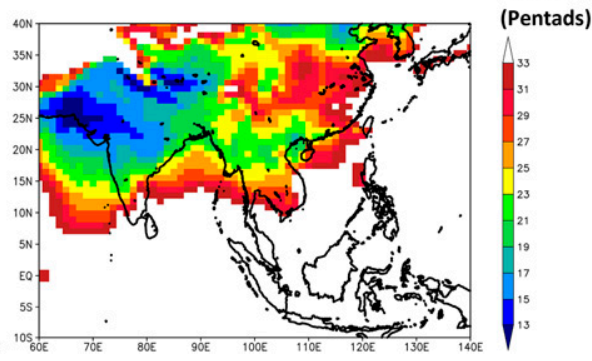

FIG. 1. (a) Monsoon intensity (shading) and the $850-\mathrm{hPa}$ wind differences between summer and winter (vectors; $\mathrm{m} \mathrm{s}^{-1}$ ) within the Asian monsoon domain (green line). Following Wang and Ding (2008), Wang et al. (2011), and Kim et al. (2011), the monsoon domain is defined as areas with annual range of precipitation $>2.5 \mathrm{~mm}_{\text {day }}{ }^{-1}$, in which the annual range of precipitation is the local summer mean minus the local winter mean (May-September mean minus November-March mean in Northern Hemisphere), while the monsoon intensity is defined as the ratio of the annual range over the annual mean precipitation. (b) Asian summer monsoon onset pentad and (c) monsoon duration based on accumulated rainfall fraction following Sperber and Annamalai (2014). The onset pentad at each grid is defined as the Julian pentad at which the accumulated rainfall $>20 \%$ of annual rainfall in the grid, while the duration is the number of pentads between the onset pentad and the pentad at which the accumulated rainfall fraction reaches $80 \%$ of annual rainfall. Results are calculated from (left) GPCP precipitation and ERA-Int wind, (center) TRMM 3B42 precipitation and ERA-Int wind, and (right) CAM5 AMIP simulations during 1998-2012.

east to west. A similar figure using the CAM5 CAPT day-3 hindcast simulations is shown in Fig. 2b. A distinct dipole pattern of bias can be found in the ocean basins mentioned above. Over the eastern part of the ocean basin, the seasonal contrast is more suppressed in the hindcasts, while over the western part of the ocean basin (leeward shore) the seasonal contrast is more enhanced. Note that over the SCS the enhanced seasonal contrast occurs over the northwestern part (i.e., coast of southern China and Taiwan Strait), while the Vietnam coastal region south of $17^{\circ} \mathrm{N}$ does not meet the threshold of observed monsoon domain. Although the synoptic-scale circulation pattern remains close to ERA-Int within 2-3 days of model integration, large biases can still arise in local circulation associated with interactions between parameterized physics and dynamics (fast physical processes) or from the interactions with the topography over the surrounding continents. Nevertheless, the bias of monsoon intensity in Figs. $2 \mathrm{a}$ and $2 \mathrm{~b}$ shows a similar east-west gradient in these coastal areas (southeast-northwest gradient in the case of SCS), with a difference in magnitude, indicating that the bias of monsoon intensity in the AMIP simulation is highly related to the bias from the fast physics. (More detailed descriptions of the correspondence between the bias in the short-range hindcasts and the AMIP bias are provided in the supplemental text and Figs. S1-S4.)

In the above results, the SCS is the region exhibiting major monsoon bias in CAM5 AMIP. The monsoon bias is further examined here over the SCS-East Asian (EA) 
(a) CAM5 AMIP

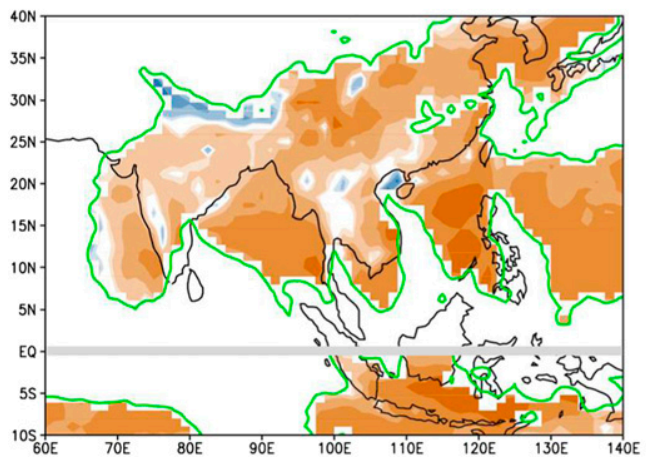

(b) CAPT DAY3

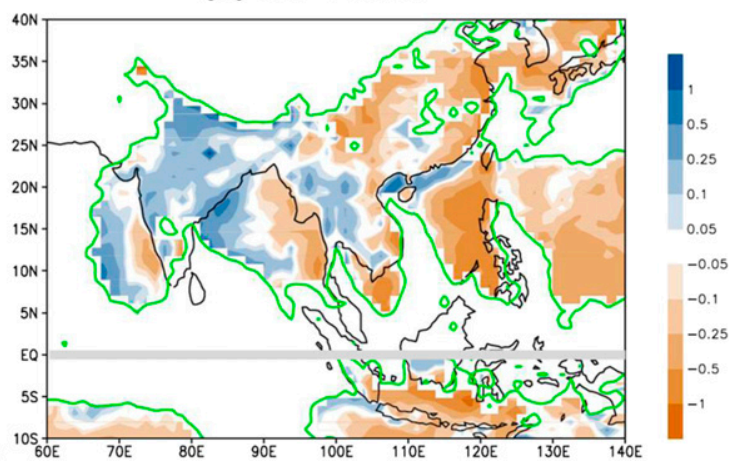

FIG. 2. Bias of monsoon intensity (shading) in (a) CAM5 AMIP simulation and (b) CAPT day-3 simulations over 1998-2012 relative to TRMM 3B42 (shading) within the Asian monsoon domain (green lines).

sector $\left(110^{\circ}-120^{\circ} \mathrm{E}\right)$ since the onset of the SCSSM signifies the onset of the broader EA-WNP summer monsoon (Hung and Hsu 2008; Tanaka 1992; Tao et al. 1987; Wang et al. 2009), and the interannual variability of SCSSM precipitation can provide an anomalous heat source, further influencing the EA, Indian, and Australian monsoons (e.g., Ding 1992; Lau and Yang 1997; Tao et al. 1987; Wang et al. 2004). The Hovmöller diagrams in Figs. $3 \mathrm{a}$ and $3 \mathrm{~b}$ characterize the climatological seasonal cycle composite of zonally averaged precipitation and 850-hPa wind fields covering SCS and EA in the observations and reanalysis. The sharp SCSSM onset is characterized by the abrupt reversal of low-level winds from northeasterly to southwesterly and coincident rainfall burst occurring around mid-May $\left(\sim 5^{\circ}-\right.$ $20^{\circ} \mathrm{N}$ ). The subsequent northward propagation of southwesterly winds and heavy rainfall is the key feature of EA summer monsoon evolution. In the CAM5 AMIP simulation (Fig. 3c), the SCSSM onset is less drastic, with earlier commencement of rainfall around mid-April, and less distinct switch in wind direction, whereas to the north in the EA the southwesterly appears too early, with weaker rainfall during the summertime. Such bias is consistent with previous studies that found the earlier onset of SCSSM to be associated with subsequently weaker EA summer monsoon (Chen et al. 2000; He and Zhu 2015).

The similar seasonal cycle composite of the multiyear CAPT day-3 hindcasts is shown in Fig. 3d. Even with the well-constrained synoptic-scale circulation, CAM5 still overestimates rainfall over SCS from late April to midMay and underestimates rainfall in the post-onset stage in the hindcast, although the magnitude of the rainfall bias is less significant than the AMIP simulations. In the next section, the CAPT hindcasts are analyzed during the 10-day periods before and after the abrupt onset each year over the SCS to understand the details of the bias associated with interactions of the fast physics parameterizations.

\section{b. Composite analyses of CAPT hindcasts during SCS monsoon onset}

The model precipitation bias is evaluated on the basis of the pre- and post-onset composites of SCS summer monsoon. The monsoon onset date was determined by the circulation-based $U_{\mathrm{SCS}}$ index (Wang et al. 2004). The climatological mean onset pentad is 27.5 ( $\sim$ mid-May) over these 15 years with an interannual standard deviation of 1.7 pentads. The $U_{\mathrm{SCS}}$ index, which is the pentad mean $u$ wind averaged over $5^{\circ}-15^{\circ} \mathrm{N}, 110^{\circ}-120^{\circ} \mathrm{E}$, is calculated also using ERA-Int in this study. To capture the presence of the large-scale westerly flow over SCS region, the onset pentad is identified each year as the $U_{\mathrm{SCS}}$ index first turns positive and persists in three out of the four subsequent pentads, with the accumulative four-pentad mean $U_{\mathrm{SCS}}$ greater than $1 \mathrm{~m} \mathrm{~s}^{-1}$. Observations and hindcasts within 10 days before (after) the onset date of each year within the available periods are averaged to obtain the pre-onset (postonset) composite. We note that during the post-onset period in the year 2006 the hindcasts simulate the formation of an unrealistically strong tropical cyclone over SCS regarding the coarse model resolution, so we subjectively excluded this year in the post-onset composite in the subsequent analyses. The nonexclusive composite is presented in Fig. S3.

Evaluation exactly targeting the pre- and post-onset periods benefits from the multiyear hindcast approach. As the synoptic-scale horizontal circulation is close to the reanalysis, defining the onset pentad according to the circulation-based index in the hindcast becomes easy and realistic. Making similar pre- and post-onset composites for AMIP simulation takes much more effort, and the results may not be comparable as the onset 
(a) GPCP PREC, ERA-I $U_{850}, V_{850}$

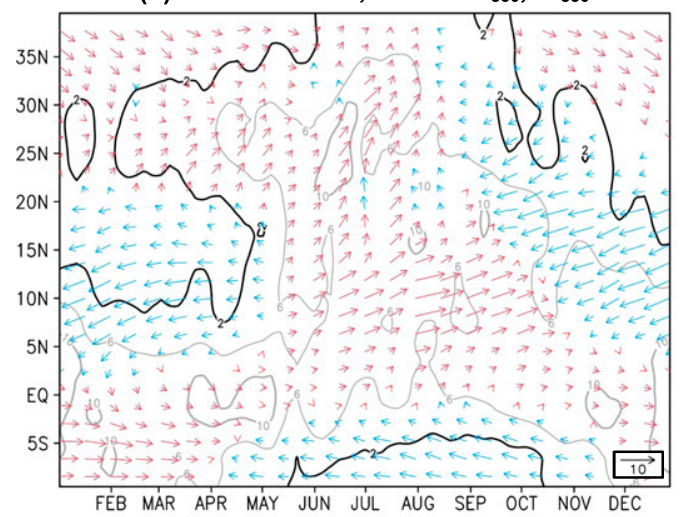

(c) CAM5 AMIP (PREC, $\mathrm{U}_{850}, \mathrm{~V}_{850}$ )

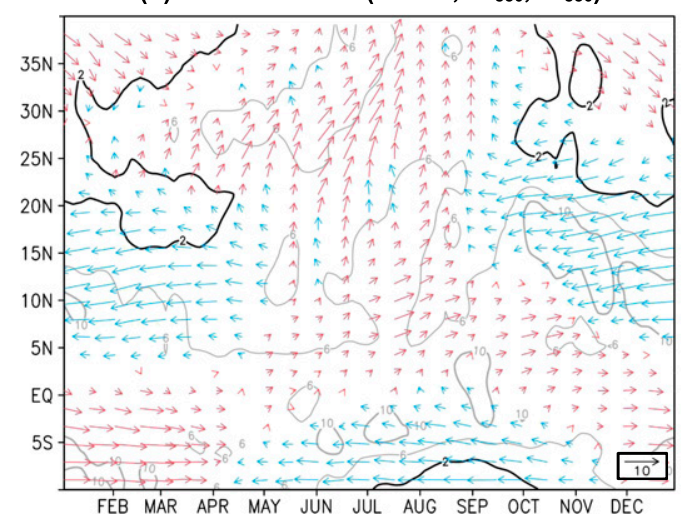

(b) TRMM PREC, ERA-I $U_{850}, \mathbf{V}_{850}$

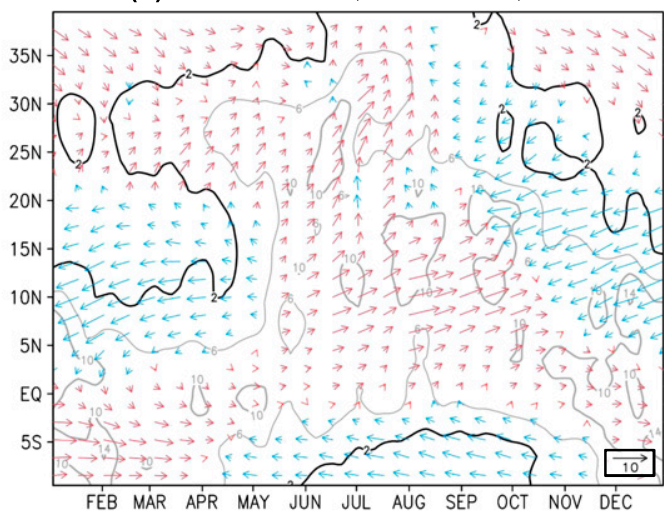

(d) CAPT DAY3 (PREC, $\mathrm{U}_{850}, \mathrm{~V}_{850}$ )

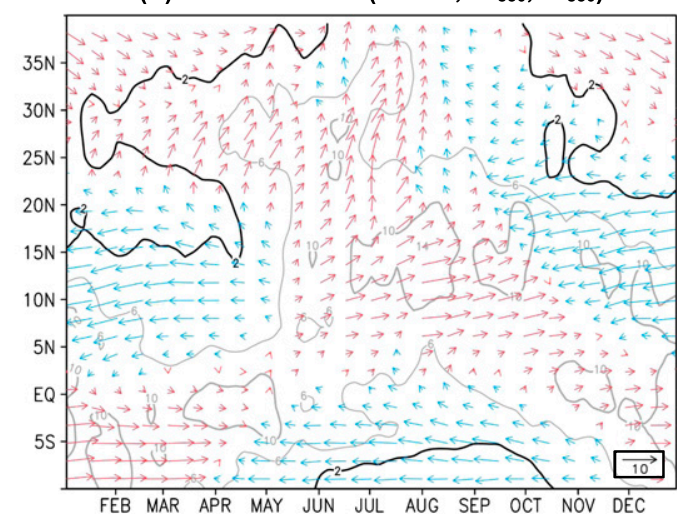

FIG. 3. Climatological latitude-time Hovmöller diagram of $850-\mathrm{hPa}$ horizontal winds (vectors; $\mathrm{m} \mathrm{s}^{-1}$; red for westerly component and blue for easterly component) and precipitation rate (contours; $\mathrm{mm} \mathrm{day}^{-1}$; thick line marks $2 \mathrm{~mm} \mathrm{day}^{-1}$, with increments of $4 \mathrm{~mm} \mathrm{day}^{-1}$ ) over East Asia during 1998-2012. All data are temporally averaged into pentads and spatially averaged between $110^{\circ}$ and $120^{\circ}$ E. Panels show (a) GPCP precipitation and ERA-Int winds, (b) TRMM 3B42 precipitation and ERA-Int winds, (c) CAM5 AMIP simulation, and (d) CAPT day-3 simulations.

timing and large-scale states can be very different from the observations. Also, the similar synoptic-scale dynamics in the hindcast enable the attribution of bias to the interactions of the fast physics.

\section{1) PRe-OnSET COMPosite}

The pre-onset composite mean precipitation and 850-hPa wind field are shown in Fig. 4. Here the observations and reanalysis are smoothed into the CAPT day-3 model grids to help with the comparison. As demonstrated by the ERA-Int winds (Fig. 4a), the SCS region (red box) exhibits mostly easterlies associated with the subtropical high ridge in the Pacific, which block the southwesterly monsoon flows from entering the East Asia region. In the TRMM precipitation composite, there is already strong precipitation over the land areas surrounding the SCS region including southern China, the east coast of Indochina, and Luzon Island, which are associated with the active diurnal cycle of convection. On the other hand, precipitation over the ocean areas of SCS is significantly suppressed. This strong land-ocean precipitation contrast is a distinct pattern in both TRMM and GPCP (not shown) during the pre-onset period over the SCS region.

In the pre-onset hindcasts composite (Fig. 4b), the wind field exhibits a similar easterly flow over SCS, showing that the synoptic-scale horizontal circulation is well constrained using the hindcast approach. However, it is evident that the hindcasts produce too much precipitation over the SCS when compared to the observation, suggesting that the atmospheric conditions over the ocean in the hindcasts are not suppressed enough during the pre-onset period. The precipitation bias over land is also significant. In the TRMM composite, precipitation over land is generally stronger over the coastal sides while in the hindcasts it is weaker and shifted toward the inland region. Another noticeable bias is that precipitation over Luzon Island is smoothly 
(a) TRMM PREC, ERA-I $\mathrm{U}_{850}, \mathrm{~V}_{850}$

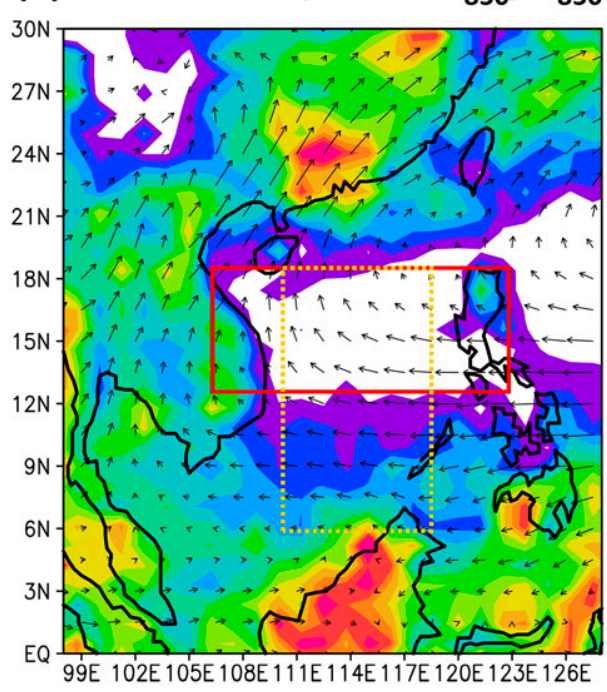

(b) CAPT DAY3

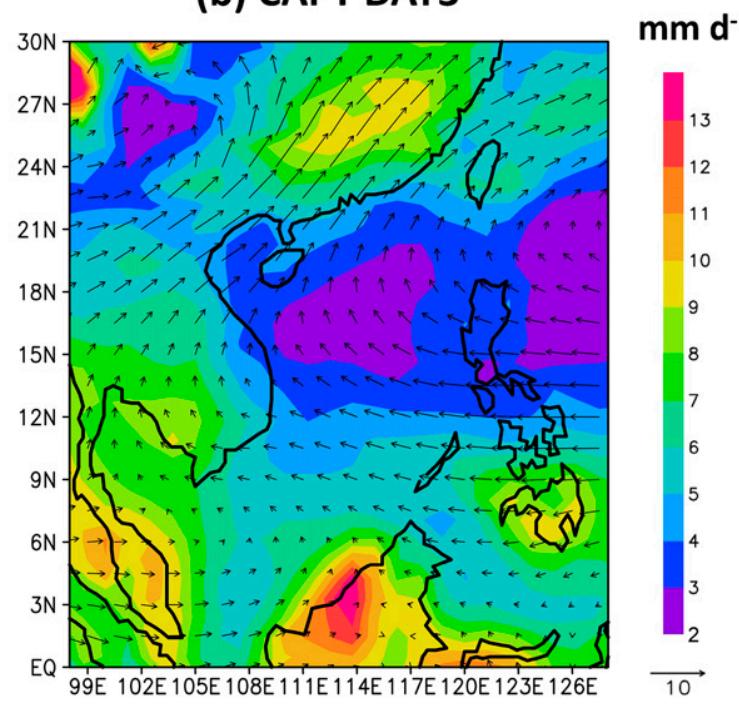

FIG. 4. Pre-onset composite of precipitation and 850-hPa horizontal wind in (a) observations (GPCP and ERAInt) and (b) CAPT day-3 simulations. The observations and reanalysis are smoothed into the CAPT day-3 model grids. In (a) the red box shows the area sampled in Figs. 5-7, 9, and 10, and the yellow box shows the area sampled in Fig. 13.

distributed in the hindcasts, probably due to the coarser resolution in the model to represent orography. The overall precipitation pattern suggests that, even with the well-constrained synoptic-scale dynamics, the CAM5 is unable to capture the land-ocean contrast of precipitation due to deficiencies in representing interactions among fast physical processes.

The zonal distribution of composite mean precipitation and column relative humidity $(\mathrm{CRH})$ is presented in Fig. 5, which is meridionally averaged over the red box in Fig. 4a. The precipitation (Fig. 5a) shows a sharp landocean gradient in both TRMM and GPCP data. The magnitude can be up to $2.5 \mathrm{~mm} \mathrm{day}^{-1}$ on the coast on the Philippine side. This gradient is much weaker in the hindcasts mainly owing to the positive precipitation bias over SCS $\left(\sim 2 \mathrm{~mm} \mathrm{day}^{-1}\right)$. The simulated precipitation over the Philippines lies within the range between the two observations, while over the Vietnam coast an underestimation can be seen. In the $\mathrm{CRH}$ distribution (Fig. 5b), a concave shape with a minimum located over the ocean can be found in the ERA-Int data, while the ocean is too moist in the hindcasts and land-ocean moisture gradient is missing.

To further explore the strong land-ocean contrast of precipitation and moisture over the SCS, we conditionally sampled the days when the ocean region exhibits low-level subsidence or weak updraft (defined as daily mean ERAInt $-\omega<0.005 \mathrm{~Pa} \mathrm{~s}^{-1}$ over $12.5^{\circ}-18.5^{\circ} \mathrm{N}, 110^{\circ}-118^{\circ} \mathrm{E}$ in all levels between 1000 and $500 \mathrm{hPa}$ ), which account for $47 \%$ (71 out of 150 days) of the pre-onset period. Figure $6 \mathrm{a}$ shows the conditioned anomalous zonal vertical winds in ERA-Int and TRMM PR Q1 - QR heating profiles. A basin-scale local circulation can be seen over the SCS region, relative to the mean zonal-vertical flow (within the red box of Fig. 4a). The strong anomalous ascending motion over the east coast of Indochina and Luzon Island is accompanied with the deep and concentrated convective heating maximizing at $500-600 \mathrm{hPa}$, while the strong anomalous subsiding motion toward the center of SCS corresponds to weak $\left(<0.5 \mathrm{~K} \mathrm{day}^{-1}\right)$ and scattered heating above $750 \mathrm{hPa}$. In the hindcasts (Fig. 6b, sampled on the same dates with the updraft of the reanalysis), the anomalous updrafts over land are shallower and Q1-QR heating is horizontally more spread out. The low-level anomalous subsidence over the ocean is weaker, with prevailing heating of 0.5$1 \mathrm{~K} \mathrm{day}^{-1}$ above $750 \mathrm{hPa}$. As the warm SST (around $29^{\circ} \mathrm{C}$ during pre-onset) provides a favorable condition for convection development, the weaker subsidence in the hindcasts is consistent with the overestimated precipitation over the SCS. We note that the heating associated with shallow cumuli is not detected by the TRMM SLH product, which likely explains the difference between the surface and the 900-hPa levels, the altitudes where the heating in the hindcasts is dominated by the shallow convection scheme.

The relationship between the strength of local circulation over the SCS basin and precipitation suppression at the ocean center can be further elaborated in Fig. 7 through the scatterplot of daily mean precipitation over 
(a) Pre-onset, Precipitation

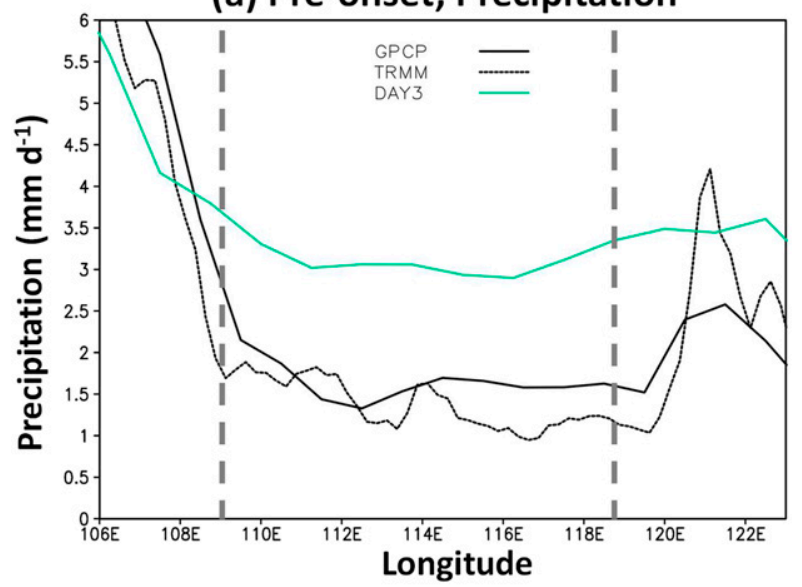

(b) Pre-onset, Column RH

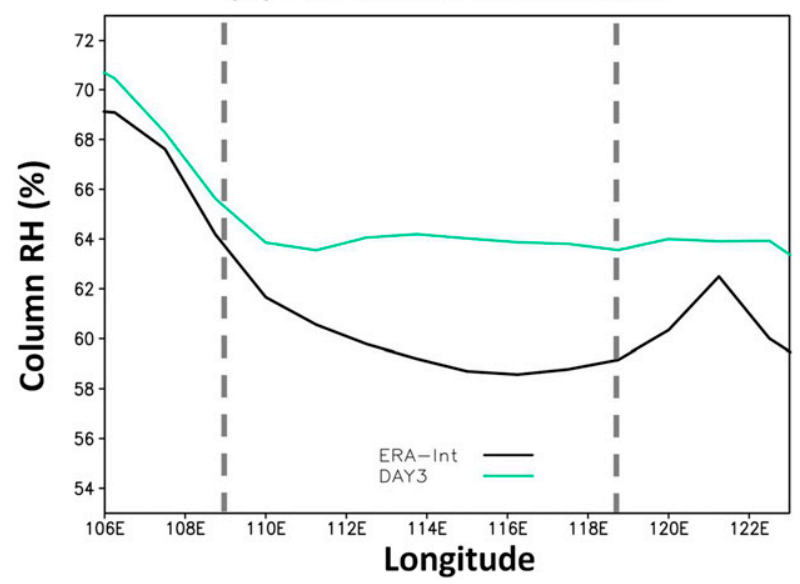

FIG. 5. Pre-onset composite mean zonal distribution of (a) precipitation and (b) column-integrated relative humidity over SCS from observations (black lines) and CAPT day-3 (green lines). Data are meridionally averaged over $12.5^{\circ}-18.5^{\circ} \mathrm{N}$ (red box in Fig. 4a). The vertical dashed lines mark the average location of the coastlines.

land versus anomalous updraft at $500 \mathrm{hPa}$ over open ocean within SCS (red box in Fig. 4a; the open ocean is defined as the area between $110^{\circ}$ and $118^{\circ} \mathrm{E}$ ). In the observational and reanalysis data (black open circles), it is clear that stronger land precipitation is associated with stronger anomalous ocean subsidence (negative values). In the hindcasts (blue crosses), the relationship between the land precipitation and ocean subsidence exists but is much weaker and uncertain.

The above results indicate that the bias of shallower and spatially less concentrated convection over the surrounding land generates a weaker basin-scale circulation, which cannot sufficiently suppress ocean precipitation, and hence produces weaker land-ocean precipitation contrast. As precipitation during this period over the surrounding land of the SCS is (a) Pre-onset, TRMM-SLH Q1-QR and u'w'

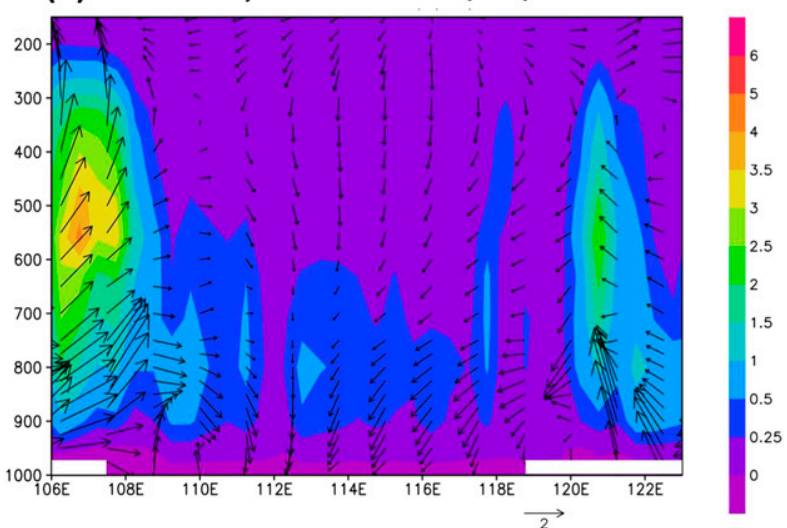

(b) Pre-onset, CAPT DAY3 Q1-QR and u'w'

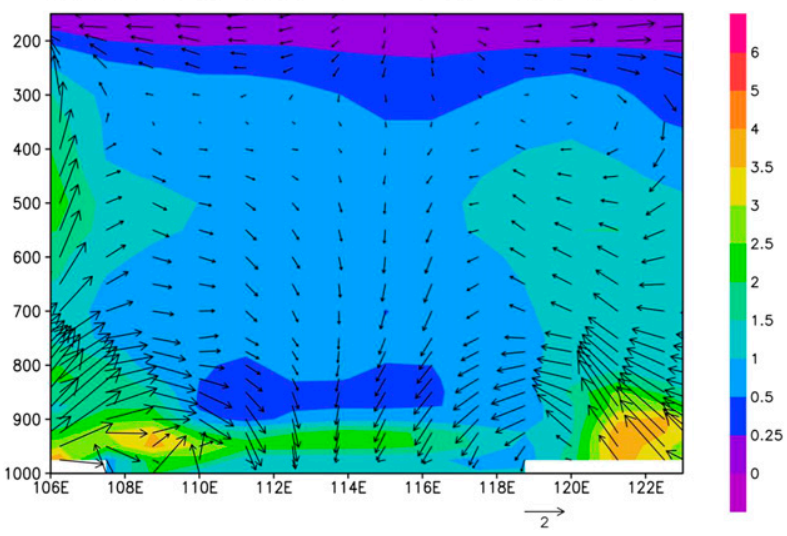

FIG. 6. Pre-onset meridional distribution of Q1 - QR diabatic heating profiles (shading; $\mathrm{K} \mathrm{day}^{-1}$ ) and anomalous zonal-vertical circulation over SCS (vectors) from (a) ERA-Int and (b) CAPT day 3. The model Q1 - QR is the sum of the temperature tendency of all physical processes excluding radiation. The vectors are the $u$ wind anomaly and $-100 \times$ omega anomaly, with units of $\mathrm{m} \mathrm{s}^{-1} \times$ $\mathrm{Pas}^{-1}$. Days are only conditionally sampled when open ocean areas exhibit low-level subsidence or weak updraft (daily mean ERA-Int $-\omega<0.005 \mathrm{~Pa} \mathrm{~s}^{-1}$ over $12.5^{\circ}-18.5^{\circ} \mathrm{N}, 110^{\circ}-118^{\circ} \mathrm{E}$ in all levels between 1000 and $500 \mathrm{hPa}$ ). The hindcasts were sampled on the same dates with the updraft of the reanalysis meridionally averaged over $12.5^{\circ}-18.5^{\circ} \mathrm{N}$ (red box in Fig. 4a), and the anomaly fields are relative to the areal average over $12.5^{\circ}-18.5^{\circ} \mathrm{N}, 106^{\circ}-$ $123^{\circ} \mathrm{E}$.

dominated by the diurnal variation, the bias of weaker and shallower land precipitation in the hindcast is likely tied to the weaker and smoother diurnal cycle of rainfall in the model, which will be discussed in section 4 in more detail.

\section{2) Post-onset composite}

Figure 8 presents the precipitation and $850-\mathrm{hPa}$ wind field composite for the post-onset period. The observational and reanalysis data (Fig. 8a) show that the southwesterly flow dominates the SCS-EA regions, and heavy precipitation occurs mainly over ocean to the west 


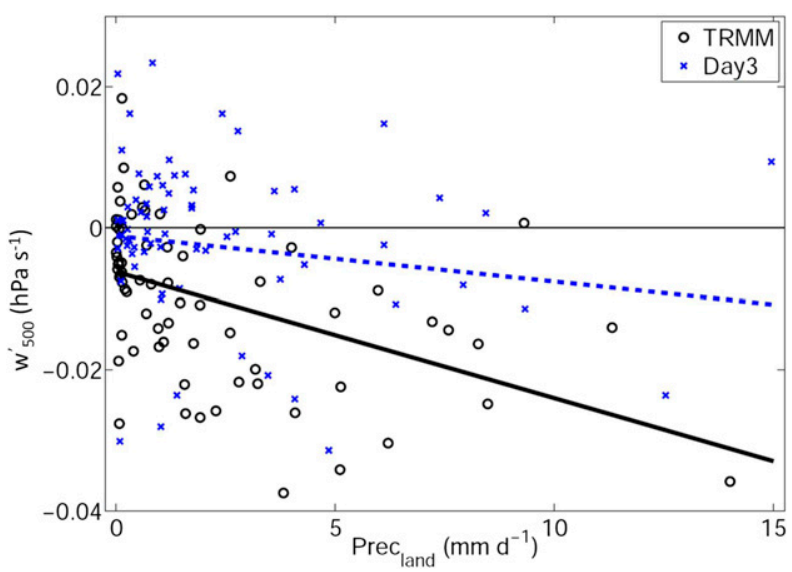

FIG. 7. Scatterplot of pre-onset daily mean precipitation over land vs updraft anomaly at $500 \mathrm{hPa}$ averaged over open ocean in the SCS (red box in Fig. 4a), with conditionally sampling of the days as in Fig. 6. Black circles are TRMM precipitation vs ERA-Int updraft anomaly, while blue crosses are CAPT day- 3 output. The black solid line (TRMM vs ERA-Int; slope $=-0.0025, R^{2}=0.53$ ) and blue dashed line (CAPT day 3 ; slope $=-0.0003, R^{2}=0.05$ ) are linear regression lines of the data points, respectively. The land areas within the red box in Fig. 4a cover Luzon Island and the east coast of Vietnam. The open ocean areas are defined here as $12.5^{\circ}$ $18.5^{\circ} \mathrm{N}, 110^{\circ}-118^{\circ} \mathrm{E}$ (red box between the two vertical yellow dashed lines in Fig. 4a). Updraft anomaly values are relative to the areal mean over $12.5^{\circ}-18.5^{\circ} \mathrm{N}, 106^{\circ}-123^{\circ} \mathrm{E}$.

of the Philippine coast. In the hindcasts (Fig. 8b), the overall synoptic-scale flow pattern remains similar to observation, with a slightly stronger southwesterly flow south of Taiwan. The simulated precipitation over the SCS is significantly weaker and spread out over the basin. The zonal distribution of precipitation over SCS in Fig. 9a, which is meridionally averaged over the red box in Fig. 4a, shows a distinct east-west gradient in both TRMM and GPCP observation. In the hindcasts, precipitation gradient is relatively weak across the domain. The zonal distribution of CRH (Fig. 9b) suggests that the environment is moist across SCS domain and the hindcasts only show a small overestimation. The heavy precipitation over the Philippine coast is mostly contributed by large, organized convective systems (e.g., Chen 2016; Ciesielski and Johnson 2006; Johnson et al. 2005; Wang and Carey 2005; Zhou et al. 2007; Xu and Rutledge 2018), which is not represented by the hindcasts appropriately, despite the moist environment. Also, these coastal organized convections are propagating mesoscale systems that are often triggered by land-sea breezes and/or the boundary layer gravity waves associated with land convection (Houze et al. 1981; Mapes et al. 2003; Mori et al. 2004; Wapler and Lane 2012; Yokoi et al. 2017). Therefore, the underestimation of heavy rainfall might also be tied to the bias in representing the land diurnal cycle, as discussed in the next section.

Figure 10 demonstrates the vertical structure of Q1 QR heating and mean circulation. In the TRMM estimation, deep convective heating occurs over both land and ocean. The ascending motion in ERA-Int vertically extends from low- to upper-level troposphere (900$300 \mathrm{hPa}$ ). In the hindcasts, the convection produces strong heating with ascending motion in the upper levels (500-300 hPa), and the "top heavy" shape of the heating profile is particularly evident over the ocean. We examined the heating tendency contributed by individual physics scheme in the model. The heating between 400 and $300 \mathrm{hPa}$ is mainly contributed by the combination of (a) TRMM PREC, ERA-I $\mathrm{U}_{850}, \mathrm{~V}_{850}$

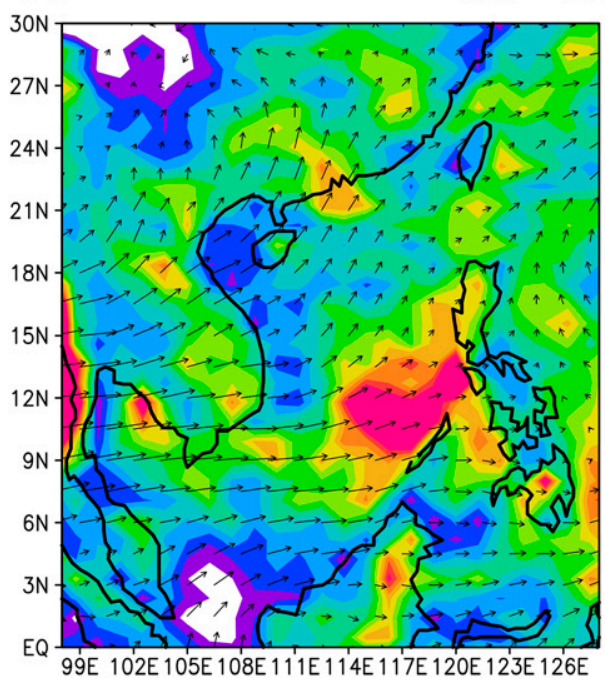

(b) CAPT DAY3

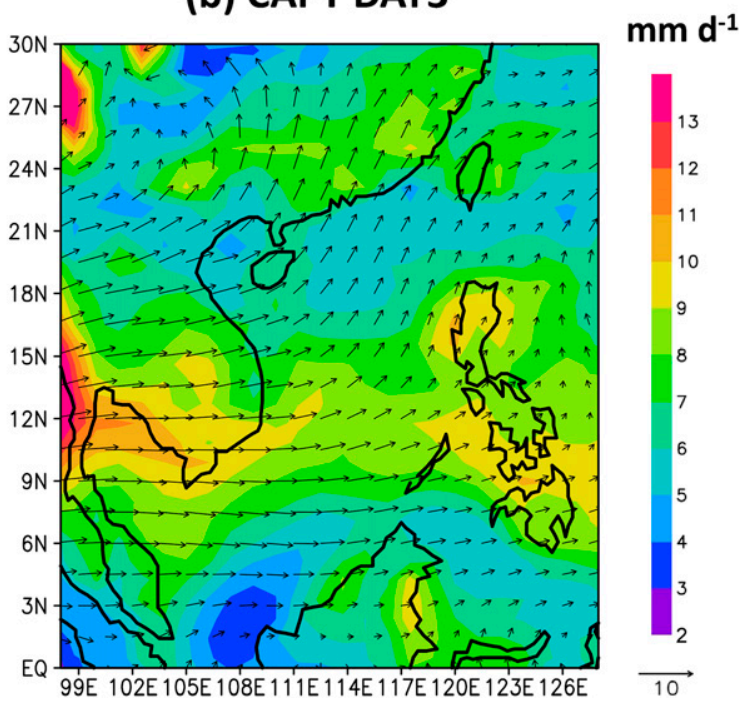

FIG. 8. As in Fig. 4, but for the post-onset composite (excluding year 2006; see text for detail). 
(a) Post-onset, Precipitation

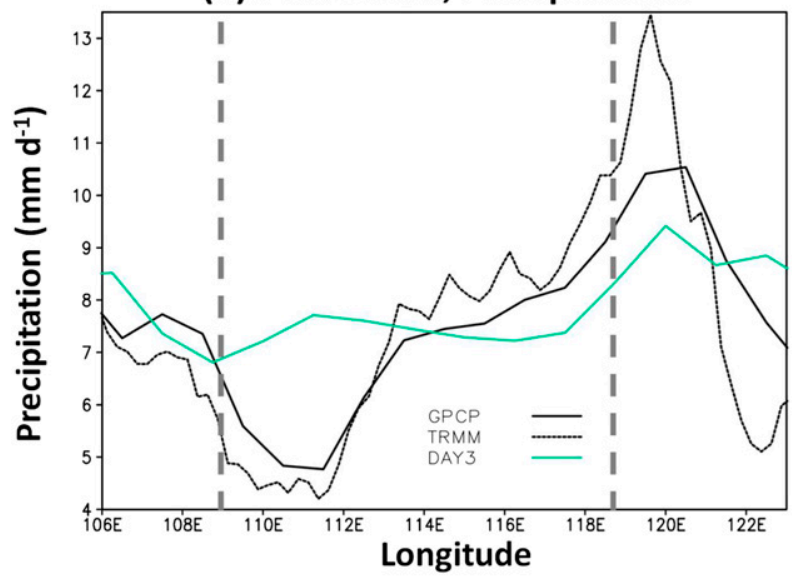

(b) Post-onset, Column RH

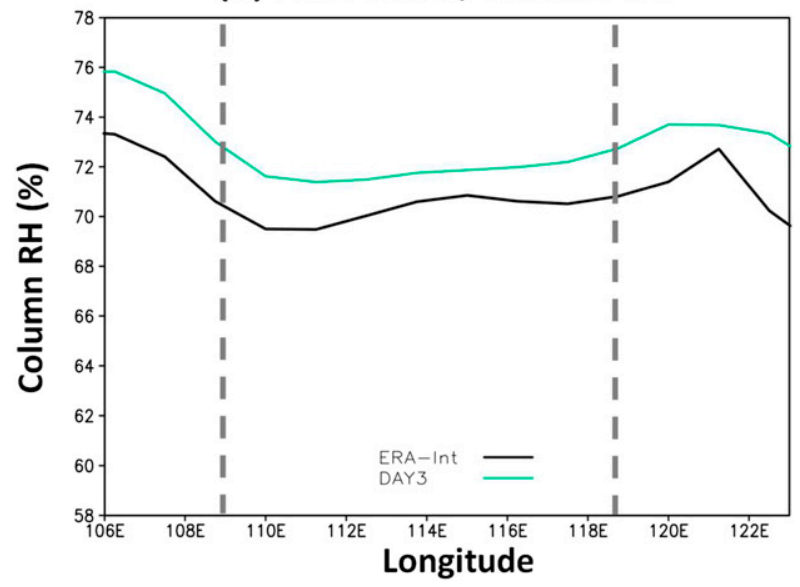

FIG. 9. As in Fig. 5, but for the post-onset composite (excluding year 2006).

the cumulus convection schemes and the macrophysics (cloud fraction) scheme. The heating contribution at $350 \mathrm{hPa}$ is shown in Fig. S5.

\section{Discussion}

As precipitation over the SCS exhibits strong diurnal variation around the onset period (Aves and Johnson 2008; Chen 2016; Chen et al. 2016; Park et al. 2011), it is worth discussing how model represents the diurnal cycle under the hindcast framework, and how this may contribute to the composite mean bias shown above. The composite diurnal evolution of precipitation during the pre-onset (Fig. 11) and post-onset (Fig. 12) periods can be compared between TRMM observation and the day-3 hindcasts. During the pre-onset period (Fig. 11a), there is a pronounced diurnal cycle over the coastal land areas surrounding the SCS with a diurnal peak greater than $24 \mathrm{~mm} \mathrm{day}^{-1}$ at around 1700 local time. This diurnal (a) Post-onset, TRMM-SLH Q1-QR and u'w'

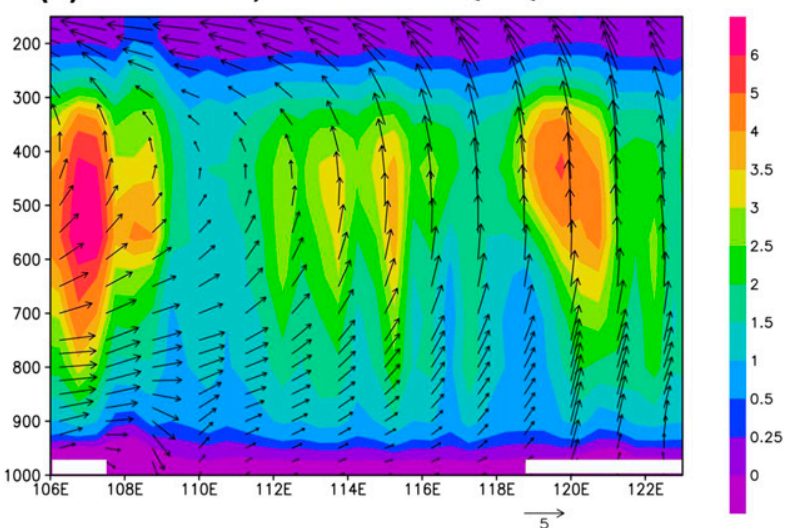

(b) Post-onset, CAPT DAY3 Q1-QR and u'w'

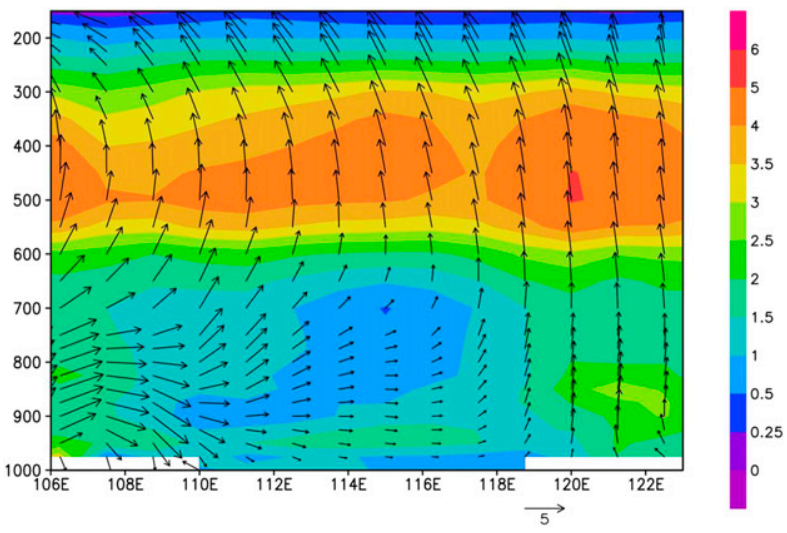

FIG. 10. As in Fig. 6, but for the post-onset composite, and the vectors show composite mean zonal-vertical circulation ( $u$ wind and $-100 \times$ omega; $\mathrm{ms}^{-1} \times \mathrm{Pa} \mathrm{s}^{-1}$ ) instead of the anomalies, shown without conditional sampling, but excluding year 2006. Note that the scale of wind vector differs from Fig. 6.

evolution is missing in the hindcasts (Fig. 11b) with weak, persistent precipitation throughout the day. This can potentially be related to problems in the cumulus parameterization including the inability to capture the transition from shallow to deep convection over land (Chaboureau et al. 2004; Derbyshire et al. 2004; Guichard et al. 2004; Kuang and Bretherton 2006; Wu et al. 2009; Chao 2013) or the inadequate design of the triggering function (Bechtold et al. 2004; Hong and Pan 1998; Jakob and Siebesma 2003; Rogers and Fritsch 1996; Wang et al. 2015; Xie et al. 2004; Xie and Zhang 2000). The underrepresentation of topographic blocking and heating effect due to the coarse resolution may also contribute to the issue (Boos and Hurley 2013; Wu et al. 2017, 2018; Wu and Hsu 2016). A spatially and diurnally more concentrated convection over land is probably more effective in producing the basinwide local circulation to suppress the ocean precipitation. A companion cloud-resolving simulation with land-ocean configuration similar to the 


\section{(a) Pre-onset, TRMM}
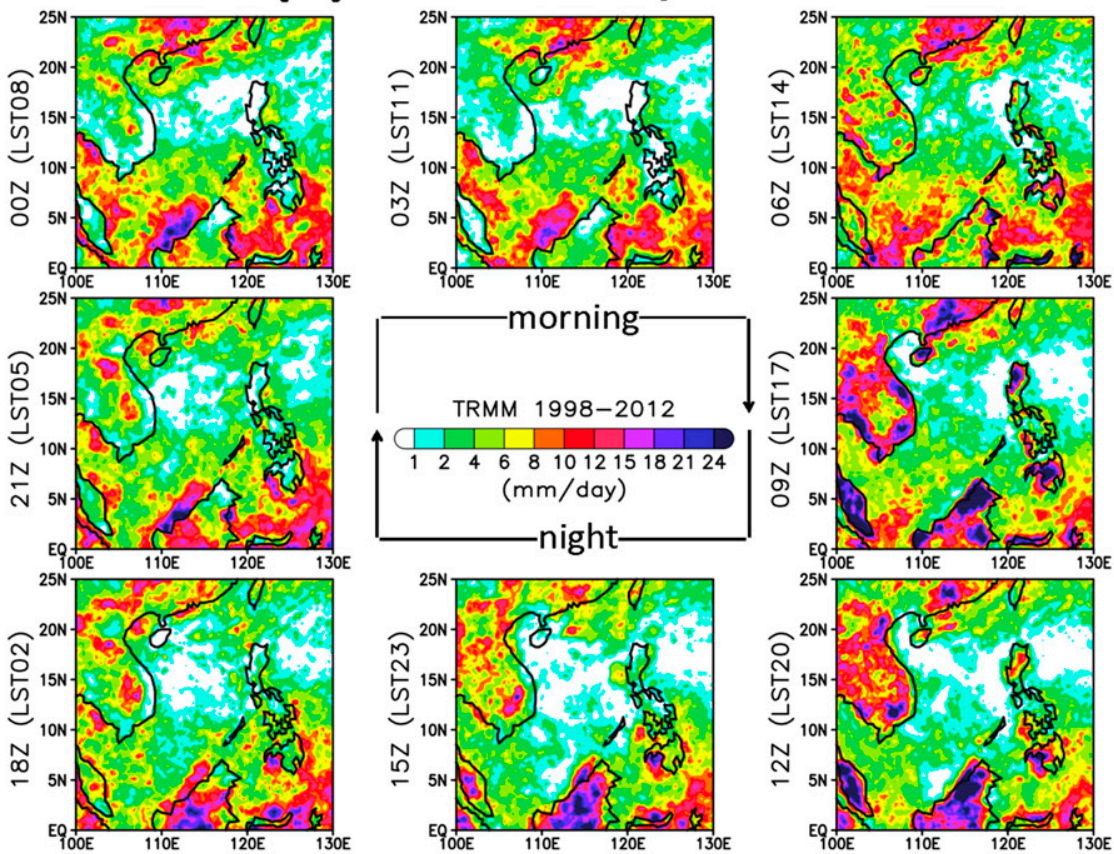

(b) Pre-onset CAPT Day3
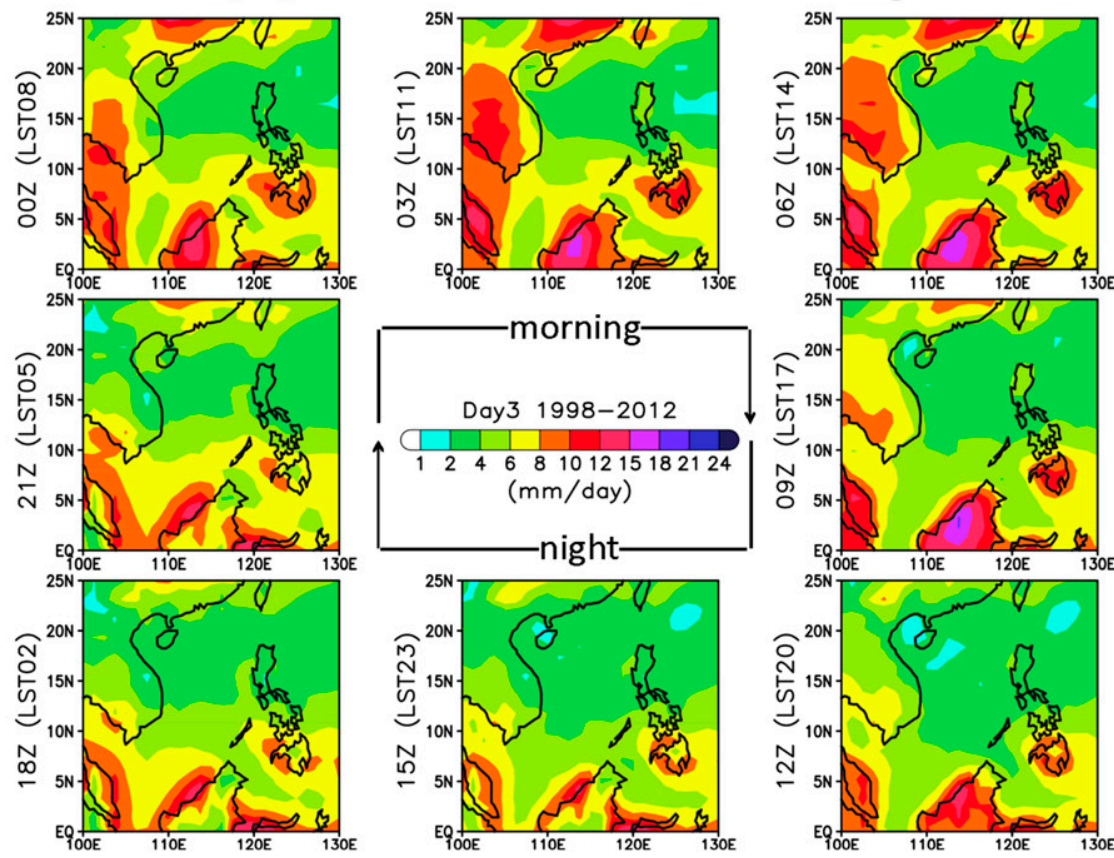

FIG. 11. Diurnal cycle of precipitation over the SCS and surrounding areas from pre-onset composites of years 1998-2012 from (a) TRMM 3B42 (shown at $0.25^{\circ}$ resolution) and (b) CAPT day-3 simulations. In (a) and (b), subpanels, clockwise from the upper-left corner, show the composite 3-hourly mean precipitation at 0000 (LST08), 0300 (LST11), 0600 (LST14), 0900 (LST17), 1200 (LST20), 1500 (LST23), 1800 (LST02), and 2100 UTC (LST05), respectively. 


\section{(a) Post-onset, TRMM}
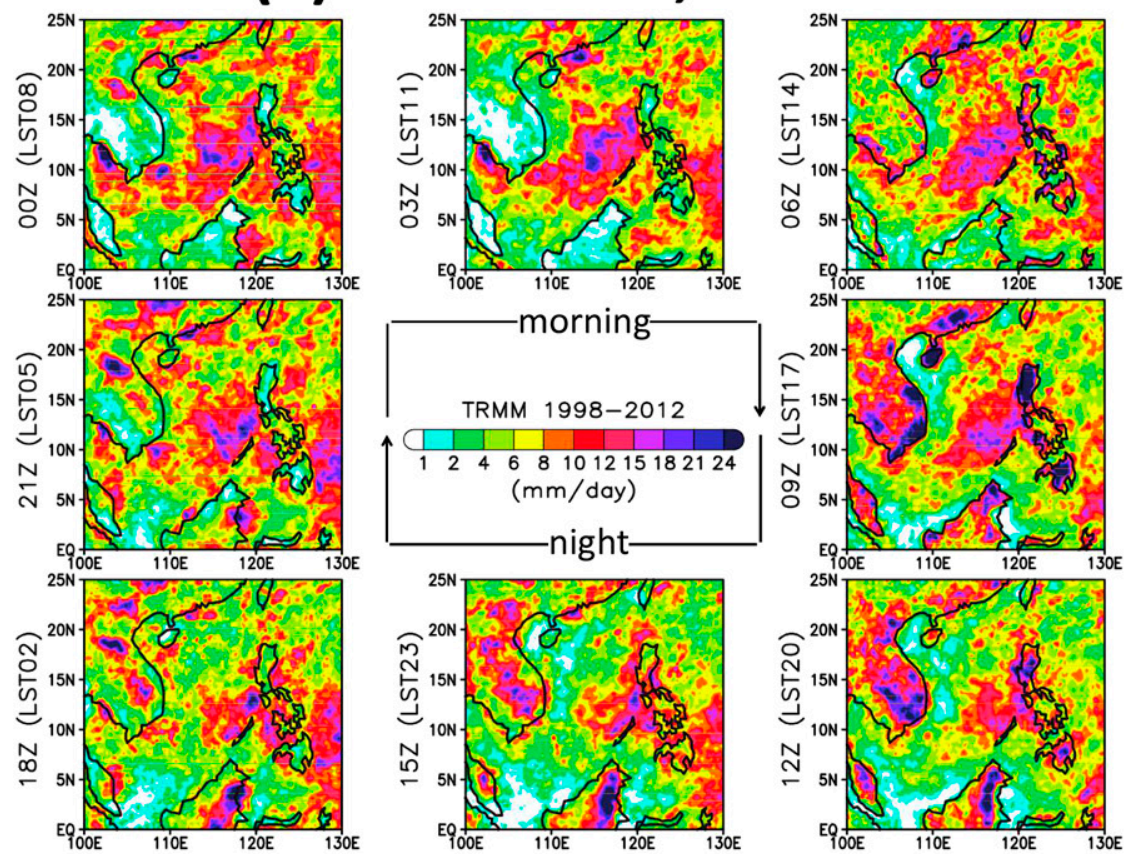

(b) Post-onset, CAPT Day3
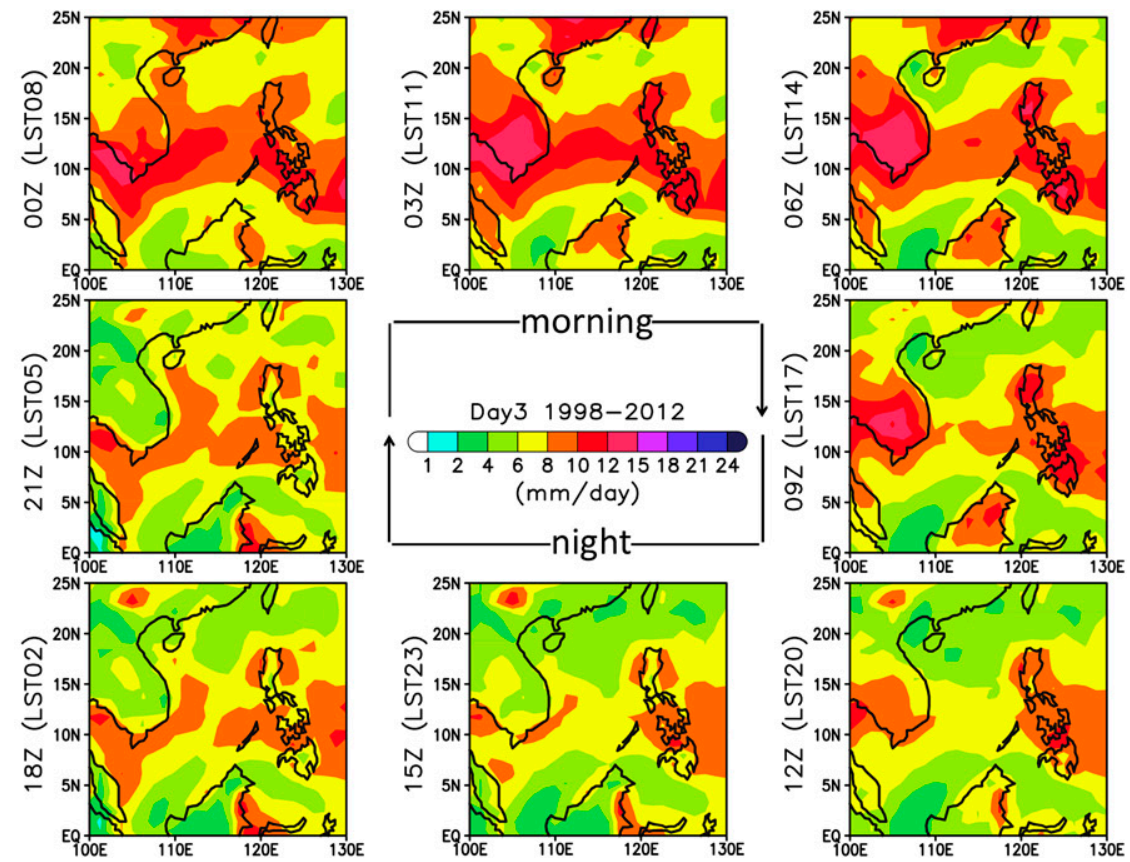

FIG. 12. As in Fig. 11, but for the post-onset composite (excluding year 2006).

scale of the SCS basin is ongoing to further confirm this anticipation.

During the post-onset period, the observed land diurnal-cycle rainfall remains prominent (Fig. 12a). The aggregated convection over the SCS off the Philippine coast also shows a clear diurnal evolution in the observation: rainfall is triggered along the coast around midnight (0200 LST), and then intensifies and propagates westward to the open ocean throughout the day. The observed propagating mesoscale convection systems 
exhibit similar features to those observed over the coastal ocean of the Maritime Continent and South America (Houze et al. 1981; Mapes et al. 2003; Mori et al. 2004; Wapler and Lane 2012; Yokoi et al. 2017). The formation of these systems, which also has a strong diurnal signal, has been linked in previous studies to the land-sea breeze and boundary layer destabilization associated with the gravity wave generated by the land convection. Also, the occurrence of the organized tropical convection is sensitive to both environmental moisture and low-level wind shear (Tsai and Wu 2017). When the land-sea breezes interact with the background southwesterly flow, which provides a vertical wind shear environment, it is possible to contribute to the development of organized convection in the coastal region. Observations in the 1998 SCSMEX indicated that the vertical wind shear is a dominant control on the oceanic convection during the onset period of the SCSSM (Johnson et al. 2005). In the hindcasts (Fig. 12b), the diurnal cycle over land is stronger than the pre-onset period but the intensity is still weaker, and the timing is shifted compared to the observation. The aggregated propagating convection over SCS is largely missing in the hindcast, with precipitation occurring on the coasts of both the Philippine and Vietnam sides. These biases can potentially relate to the fact that the land diurnal cycle and land-sea breeze are not properly resolved with the coarse GCM grid size, and/or the convective parameterizations are not sufficiently sensitive to the environmental wind shear.

The precipitation bias can also be examined from the perspective of precipitation sensitivity to environmental moisture. The precipitation should be small when CRH is low and followed by a critical transition at high $\mathrm{CRH}$, even on the basis of daily mean statistics (Kuo et al. 2017). The dependency can be viewed as the selforganized criticality of the deep convection when a critical CRH is met, and such behavior can have a strong connection to entrainment rate (Holloway and Neelin 2010; Kuo et al. 2017; Neelin et al. 2009). Figure 13 examines the relationship between CRH versus the precipitation during the pre-onset (Fig. 13a) and post-onset (Fig. 13b) periods for observation and the hindcasts. The statistics are collected grid by grid over a broader ocean area covering SCS, marked by the yellow dashed box in Fig. 4a. The stronger sensitivity is evident in ERA-Int versus observational precipitation in both the pre- and post-onset periods. In the hindcast simulation, there is more precipitation in the low $\mathrm{CRH}(50 \%-75 \%)$ regimes during the pre-onset period. During the post-onset period, given the high $\mathrm{CRH}$ environment $(>80 \%)$, the model precipitation exhibits mean values close to the observed estimates, but with much smaller variability. (a) Pre-onset

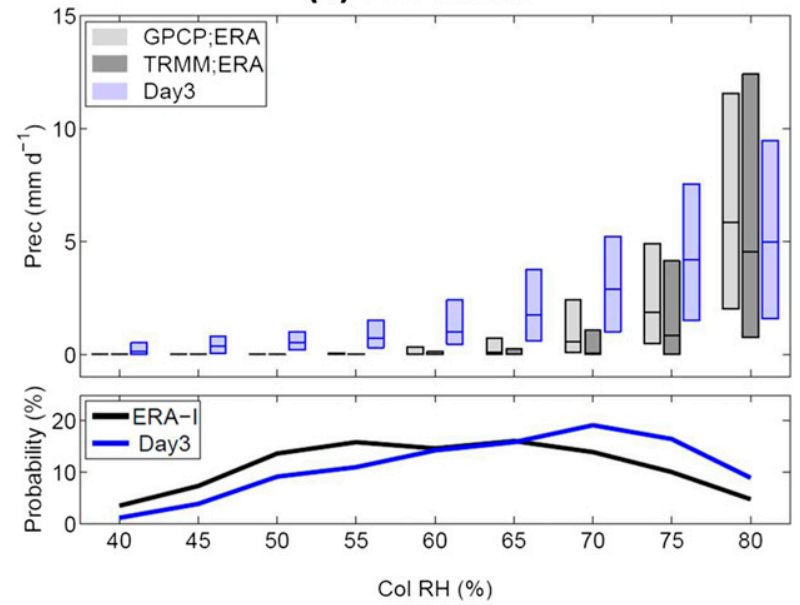

(b) Post-onset

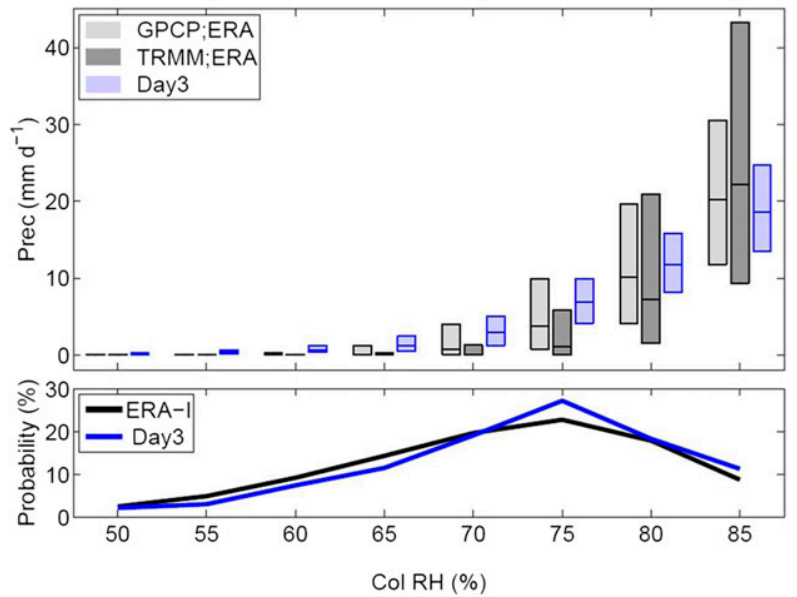

FIG. 13. (a) (top) Pre-onset daily precipitation conditionally sampled by column relative humidity $(\mathrm{CRH})$ at grids within SCS $\left(6^{\circ}-18.5^{\circ} \mathrm{N}, 110^{\circ}-118^{\circ} \mathrm{E}\right.$; yellow dashed box in Fig. $\left.4 \mathrm{a}\right)$ from observations (gray bars) and CAPT day 3 (blue bars), only sampling the days when open ocean areas exhibit low-level subsidence or weak updraft (as in Fig. 6). Observational precipitation data from GPCP (light gray bars) and TRMM 3B42 (dark gray bars) are both displayed and sampled by CRH from ERA-Int, all interpolated to same horizontal resolution as CAM5. At each CRH interval, the vertical bar spans the range from the first to the third quantiles, while the horizontal line shows the median value of the precipitation rate. (bottom) The probability density function of CRH in the top panel for ERA-Int (black line) and CAPT day 3 (blue line). (b) As in (a), but for post-onset composites (without conditional sampling, but excluding year 2006).

The result is consistent with previous studies (Del Genio et al. 2012; Derbyshire et al. 2004) showing that the sensitivity of convective parameterization to the environmental moisture is not sufficient. Although entrainment has already been considered in the convection scheme of CAM5 to improve such sensitivity, our results indicate the fundamental challenge to represent such a 
sharp transition by the cumulus parameterization in both the pre- and post-onset periods, and different signs of precipitation bias emerge under different large-scale moisture states. When weak precipitation is triggered too easily in the model under moderate CRH conditions, the moisture is consumed too quickly and cannot be properly accumulated; an even higher CRH is thus needed to produce intense rainfall.

\section{Conclusions and summary}

As the EA and SCS summer monsoon rainfall in the CAM5 AMIP simulation generally exhibits a "too early, too weak" bias, the present study identifies the contribution of the interactions among the fast physical processes to such bias. The multiyear hindcasts allow for evaluating the simulated monsoon system given wellconstrained synoptic-scale winds at the exact period surrounding the abrupt onset each year over the SCS, a key precursor of the overall EA summer monsoon onset. Compared with the observation data, CAM5 is unable to capture the land-ocean precipitation contrasts around SCS during the monsoon onset. In the pre-onset period, the warm ocean environment is usually suppressed by the subsidence associated with the basin-scale local circulation. With shallower vertical heating and a weaker diurnal cycle over land, CAM5 produces stronger precipitation over the ocean consistent with weaker subsidence. With high sea surface temperature over the SCS, the early development of precipitation is likely to promote an early EASM onset. In the post-onset period, the convective systems tend to aggregate and produce strong precipitation over the coastal ocean near the Philippines. The heavy rainfall is underestimated in CAM5 hindcasts with an overestimated upper-level heating, which can be associated with the overall weaker EASM rainfall. These biases were further manifested by the fact that the model fails to capture the timing and amplitude of the diurnal cycle, and the challenge of realistically representing the precipitation-moisture sensitivity by the parameterizations during the SCSSM onset period.

The present results indicate that with the weaker diurnal-cycle convection over land, the basin-scale local circulation and the land-ocean contrast might be underrepresented in the model. This argument can be further investigated using a similar hindcast approach with sensitivity tests on the cumulus parameterization, such as the modification of the triggering function, to see if the improvement of the diurnal cycle of land conditions can improve the local circulation. Experiments with higher horizontal resolution can also be carried out to investigate the effects when local topography is better resolved.
The present results also give prominence to the importance of land-ocean-convection interactions and coastal convection systems when simulating the precipitation during the seasonal transition over the major monsoon regions. These are also the major scientific themes of several extensive international field campaigns that are recently ongoing, including the Years of the Maritime Continent (YMC; 2017-19; see http://www.bmkg.go.id/ymc/ and http://www.jamstec.go.jp/ymc/), the South China Sea Two-Island Monsoon Experiment (SCSTIMX; 2016-19; Lin et al. 2016; see https://scstimx.as.ntu.edu.tw/), and the Propagation of Intra-Seasonal Tropical Oscillations (PISTON; 2018-19; https://onrpiston.colostate.edu/). The associated intensive field observations and cloudresolving modeling activities are particularly helpful to advance the understandings to the processes controlling the responses of the coastal diurnal convection to the large-scale condition of moisture and wind shear, as well as the upscale effects of the organized coastal systems during the transition period of the large-scale states.

Acknowledgments. Wei-Ting Chen and Chien-Ming Wu are supported by Ministry of Science and Technology of Taiwan (MOST107-2119-M-002-053, MOST106-2111M-002-005, and MOST107-2119-M-002-024). Hsi-Yen Ma was funded by the U.S. Department of Energy Regional and Global Model Analysis and Atmospheric System Research Programs, and this work was also performed under the auspices of the U.S. DOE by LLNL under Contract DE-AC52-07NA27344. The authors acknowledge Mr. Wei-Hua Hsu at NTUAS for his assistance with the production of Fig. 1. We also thank the three anonymous reviewers for their insightful comments.

The datasets analyzed in the present study can be accessed through the following repositories:

GPCP: ftp://meso.gsfc.nasa.gov/pub/1dd-v1.2/

TRMM 3B42: https://pmm.nasa.gov/data-access/downloads/ trmm

TRMM SLH: http://www.eorc.jaxa.jp/TRMM/lh/index.html ERA-Int: http://apps.ecmwf.int/datasets/data/interim-fulldaily/levtype $=$ sfc $/$

The CAM5 CAPT hindcast simulations are available online through the NERSC Science Gateways (https:// portal.nersc.gov/). Due to the large volume of data sets and limited disk space, data will be shared online upon request.

\section{REFERENCES}

Annamalai, H., K. Hamilton, and K. R. Sperber, 2007: The South Asian summer monsoon and its relationship with ENSO in the IPCC AR4 simulations. J. Climate, 20, 1071-1092, https:// doi.org/10.1175/JCLI4035.1.

, B. Taguchi, J. P. McCreary, M. Nagura, and T. Miyama, 2017: Systematic errors in South Asian monsoon simulation: Importance 
of equatorial Indian Ocean processes. J. Climate, 30, 8159-8178, https://doi.org/10.1175/JCLI-D-16-0573.1.

Aves, S., and R. H. Johnson, 2008: The diurnal cycle of convection over the northern South China Sea. J. Meteor. Soc. Japan, 86, 919-934, https://doi.org/10.2151/jmsj.86.919.

Bechtold, P., J.-P. Chaboureau, A. Beljaars, A. K. Betts, M. Köhler, M. Miller, and J.-L. Redelsperger, 2004: The simulation of the diurnal cycle of convective precipitation over land in a global model. Quart. J. Roy. Meteor. Soc., 130, 3119 3137, https://doi.org/10.1256/qj.03.103.

Boos, W. R., and J. V. Hurley, 2013: Thermodynamic bias in the multimodel mean boreal summer monsoon. J. Climate, 26, 2279-2287, https://doi.org/10.1175/JCLI-D-12-00493.1.

Bretherton, C. S., and S. Park, 2009: A new moist turbulence parameterization in the Community Atmosphere Model. J. Climate, 22, 3422-3448, https://doi.org/10.1175/2008JCLI2556.1.

Chaboureau, J.-P., F. Guichard, J.-L. Redelsperger, and J.-P. Lafore, 2004: The role of stability and moisture in the diurnal cycle of convection over land. Quart. J. Roy. Meteor. Soc., 130, 3105-3117, https://doi.org/10.1256/qj.03.132.

Chao, W. C., 2013: Catastrophe-concept-based cumulus parameterization: Correction of systematic errors in the precipitation diurnal cycle over land in a GCM. J. Atmos. Sci., 70, 35993614, https://doi.org/10.1175/JAS-D-13-022.1.

Chen, P.-J., 2016: Diurnal variation of convection over South China Sea region during summer monsoon onset. National Taiwan University, 67 pp., https://doi.org/10.6342/NTU201603207.

Chen, T.-C., M.-C. Yen, and S.-P. Weng, 2000: Interaction between the summer monsoons in East Asia and the South China Sea: Intraseasonal monsoon modes. J. Atmos. Sci., 57, 1373-1392, https://doi.org/10.1175/1520-0469(2000)057<1373: IBTSMI $>2.0 . \mathrm{CO} ; 2$.

Chen, X., F. Zhang, and K. Zhao, 2016: Diurnal variations of the land-sea breeze and its related precipitation over south China. J. Atmos. Sci., 73, 4793-4815, https://doi.org/10.1175/JAS-D16-0106.1.

Christensen, J. H., and Coauthors, 2013: Climate phenomena and their relevance for future regional climate change. Climate Change 2013: The Physical Science Basis, T. F. Stocker et al., Eds., Cambridge University Pres, 1217-1308.

Ciesielski, P. E., and R. H. Johnson, 2006: Contrasting characteristics of convection over the northern and southern South China Sea during SCSMEX. Mon. Wea. Rev., 134, 1041-1062, https://doi.org/10.1175/MWR3113.1.

Cook, K. H., G. A. Meehl, and J. M. Arblaster, 2012: Monsoon regimes and processes in CCSM4. Part II: African and American monsoon systems. J. Climate, 25, 2609-2621, https:// doi.org/10.1175/JCLI-D-11-00185.1.

Dee, D. P., and Coauthors, 2011: The ERA-Interim reanalysis: Configuration and performance of the data assimilation system. Quart. J. Roy. Meteor. Soc., 137, 553-597, https://doi.org/ 10.1002/qj.828.

Del Genio, A. D., Y. Chen, D. Kim, and M.-S. Yao, 2012: The MJO transition from shallow to deep convection in CloudSat CALIPSO data and GISS GCM simulations. J. Climate, 25, 3755-3770, https://doi.org/10.1175/JCLI-D-11-00384.1.

Derbyshire, S. H., I. Beau, P. Bechtold, J.-Y. Grandpeix, J.-M. Piriou, J.-L. Redelsperger, and P. M. M. Soares, 2004: Sensitivity of moist convection to environmental humidity. Quart. J. Roy. Meteor. Soc., 130, 3055-3079, https://doi.org/10.1256/ qj.03.130.

Ding, Y., 1992: Summer monsoon rainfalls in China. J. Meteor. Soc. Japan, 70, 373-396, https://doi.org/10.2151/jmsj1965.70.1B_373.
Gettelman, A., and Coauthors, 2010: Global simulations of ice nucleation and ice supersaturation with an improved cloud scheme in the Community Atmosphere Model. J. Geophys. Res., 115, D18216, https://doi.org/10.1029/ 2009JD013797.

Guichard, F., and Coauthors, 2004: Modelling the diurnal cycle of deep precipitating convection over land with cloud-resolving models and single-column models. Quart. J. Roy. Meteor. Soc., 130, 3139-3172, https://doi.org/10.1256/qj.03.145.

He, J., and Z. Zhu, 2015: The relation of South China Sea monsoon onset with the subsequent rainfall over the subtropical East Asia. Int. J. Climatol., 35, 4547-4556, https://doi.org/10.1002/ joc. 4305 .

Holloway, C. E., and J. D. Neelin, 2010: Temporal relations of column water vapor and tropical precipitation. J. Atmos. Sci., 67, 1091-1105, https://doi.org/10.1175/2009JAS3284.1.

Hong, S.-Y., and H.-L. Pan, 1998: Convective trigger function for a mass-flux cumulus parameterization scheme. Mon. Wea. Rev., 126, 2599-2620, https://doi.org/10.1175/1520-0493(1998) 126<2599:CTFFAM >2.0.CO;2.

Houze, R. A., S. G. Geotis, F. D. Marks, and A. K. West, 1981: Winter monsoon convection in the vicinity of north Borneo. Part I: Structure and time variation of the clouds and precipitation. Mon. Wea. Rev., 109, 1595-1614, https://doi.org/ 10.1175/1520-0493(1981)109<1595:WMCITV>2.0.CO;2.

Huffman, G. J., and Coauthors, 1997: The Global Precipitation Climatology Project (GPCP) combined precipitation dataset. Bull. Amer. Meteor. Soc., 78, 5-20, https://doi.org/10.1175/ 1520-0477(1997)078<0005:TGPCPG > 2.0.CO;2.

, R. F. Adler, M. M. Morrissey, D. T. Bolvin, S. Curtis, R. Joyce, B. McGavock, and J. Susskind, 2001: Global precipitation at one-degree daily resolution from multisatellite observations. J. Hydrometeor., 2, 36-50, https://doi.org/ 10.1175/1525-7541(2001)002<0036:GPAODD>2.0.CO;2.

, D. T. Bolvin, and E. J. Nelkin, 2010: The TRMM MultiSatellite Precipitation Analysis (TMPA). Satellite Rainfall Applications for Surface Hydrology, M. Gebremichael and F. Hossain, Eds., Springer, 3-22, http://link.springer.com/chapter/ 10.1007/978-90-481-2915-7_1.

Hung, C., and H.-H. Hsu, 2008: The first transition of the Asian summer monsoon, intraseasonal oscillation, and Taiwan mei-yu. J. Climate, 21, 1552-1568, https://doi.org/10.1175/ 2007JCLI1457.1.

Iacono, M. J., J. S. Delamere, E. J. Mlawer, M. W. Shephard, S. A. Clough, and W. D. Collins, 2008: Radiative forcing by longlived greenhouse gases: Calculations with the AER radiative transfer models. J. Geophys. Res., 113, D13103, https://doi.org/ 10.1029/2008JD009944.

Jakob, C., and A. P. Siebesma, 2003: A new subcloud model for massflux convection schemes: Influence on triggering, updraft properties, and model climate. Mon. Wea. Rev., 131, 2765-2778, https:// doi.org/10.1175/1520-0493(2003)131<2765:ANSMFM>2.0.CO;2.

Johnson, R. H., and P. E. Ciesielski, 2002: Characteristics of the 1998 summer monsoon onset over the northern South China Sea. J. Meteor. Soc. Japan, 80, 561-578, https://doi.org/10.2151/ jmsj.80.561.

, S. L. Aves, P. E. Ciesielski, and T. D. Keenan, 2005: Organization of oceanic convection during the onset of the 1998 East Asian summer monsoon. Mon. Wea. Rev., 133, 131-148, https://doi.org/10.1175/MWR-2843.1.

Kim, H.-J., K. Takata, B. Wang, M. Watanabe, M. Kimoto, T. Yokohata, and T. Yasunari, 2011: Global monsoon, El Niño, and their interannual linkage simulated by MIROC5 
and the CMIP3 CGCMs. J. Climate, 24, 5604-5618, https:// doi.org/10.1175/2011JCLI4132.1.

Kitoh, A., H. Endo, K. Krishna Kumar, I. F. A. Cavalcanti, P. Goswami, and T. Zhou, 2013: Monsoons in a changing world: A regional perspective in a global context. J. Geophys. Res. Atmos., 118, 3053-3065, https://doi.org/10.1002/jgrd.50258.

Kuang, Z., and C. S. Bretherton, 2006: A mass-flux scheme view of a high-resolution simulation of a transition from shallow to deep cumulus convection. J. Atmos. Sci., 63, 1895-1909, https://doi.org/10.1175/JAS3723.1.

Kummerow, C., and Coauthors, 2000: The status of the Tropical Rainfall Measuring Mission (TRMM) after two years in orbit. J. Appl. Meteor., 39, 1965-1982, https://doi.org/10.1175/15200450(2001)040<1965:TSOTTR $>2.0$. CO;2.

Kuo, Y.-H., J. D. Neelin, and C. R. Mechoso, 2017: Tropical convective transition statistics and causality in the water vaporprecipitation relation. J. Atmos. Sci., 74, 915-931, https:// doi.org/10.1175/JAS-D-16-0182.1.

Lau, K.-M., and S. Yang, 1997: Climatology and interannual variability of the Southeast Asian summer monsoon. Adv. Atmos. Sci., 14, 141-162, https://doi.org/10.1007/s00376-997-0016-y.

Lin, P.-H., and Coauthors, 2016: Interaction of convection over the Maritime Continent-SCS with large-scale flow: 2016 Winter Monsoon Pre-experiment. Atmos. Sci., 44, 237-352.

Liu, X., and Coauthors, 2012: Toward a minimal representation of aerosols in climate models: Description and evaluation in the Community Atmosphere Model CAM5. Geosci. Model Dev., 5, 709-739, https://doi.org/10.5194/gmd-5-7092012.

Ma, H.-Y., S. Xie, J. S. Boyle, S. A. Klein, and Y. Zhang, 2013: Metrics and diagnostics for precipitation-related processes in climate model short-range hindcasts. J. Climate, 26, 15161534, https://doi.org/10.1175/JCLI-D-12-00235.1.

__ , and Coauthors, 2014: On the correspondence between mean forecast errors and climate errors in CMIP5 models. J. Climate, 27, 1781-1798, https://doi.org/10.1175/JCLI-D13-00474.1.

— evaluation and diagnosis of physical processes in global climate models. J. Adv. Model. Earth Syst., 7, 1810-1827, https:// doi.org/10.1002/2015MS000490.

Mapes, B. E., T. T. Warner, and M. Xu, 2003: Diurnal patterns of rainfall in northwestern South America. Part III: Diurnal gravity waves and nocturnal convection offshore. Mon. Wea. Rev., 131, 830-844, https://doi.org/10.1175/1520-0493(2003) $131<0830$ :DPORIN $>2.0$. CO; 2 .

Mori, S., and Coauthors, 2004: Diurnal land-sea rainfall peak migration over Sumatera Island, Indonesian Maritime Continent, observed by TRMM satellite and intensive rawinsonde soundings. Mon. Wea. Rev., 132, 2021-2039, https://doi.org/ 10.1175/1520-0493(2004)132<2021:DLRPMO>2.0.CO;2.

Morrison, H., and A. Gettelman, 2008: A new two-moment bulk stratiform cloud microphysics scheme in the Community Atmosphere Model, version 3 (CAM3). Part I: Description and numerical tests. J. Climate, 21, 3642-3659, https://doi.org/ 10.1175/2008JCLI2105.1.

Neale, R. B., J. H. Richter, and M. Jochum, 2008: The impact of convection on ENSO: From a delayed oscillator to a series of events. J. Climate, 21, 5904-5924, https://doi.org/10.1175/ 2008JCLI2244.1.

Neelin, J. D., O. Peters, and K. Hales, 2009: The transition to strong convection. J. Atmos. Sci., 66, 2367-2384, https://doi.org/ 10.1175/2009JAS2962.1.
Park, M.-S., C.-H. Ho, J. Kim, and R. L. Elsberry, 2011: Diurnal circulations and their multi-scale interaction leading to rainfall over the South China Sea upstream of the Philippines during intraseasonal monsoon westerly wind bursts. Climate Dyn., 37, 1483-1499, https://doi.org/10.1007/s00382010-0922-z.

Park, S., and C. S. Bretherton, 2009: The University of Washington shallow convection and moist turbulence schemes and their impact on climate simulations with the Community Atmosphere Model. J. Climate, 22, 3449-3469, https://doi.org/ 10.1175/2008JCLI2557.1.

,-- , and P. J. Rasch, 2014: Integrating cloud processes in the Community Atmosphere Model, version 5. J. Climate, 27, 6821-6856, https://doi.org/10.1175/JCLI-D-14-00087.1.

Phillips, T. J., and Coauthors, 2004: Evaluating parameterizations in general circulation models: Climate simulation meets weather prediction. Bull. Amer. Meteor. Soc., 85, 1903-1915, https://doi.org/10.1175/BAMS-85-12-1903.

Randall, D. A., and Coauthors, 2007: Climate models and their evaluation. Climate Change 2007: The Physical Science Basis, S. Solomon et al., Eds., Cambridge University Press, 589-662.

Reynolds, R. W., N. A. Rayner, T. M. Smith, D. C. Stokes, and W. Wang, 2002: An improved in situ and satellite SST analysis for climate. J. Climate, 15, 1609-1625, https://doi.org/10.1175/ 1520-0442(2002)015<1609:AIISAS>2.0.CO;2.

Rogers, R. F., and J. M. Fritsch, 1996: A general framework for convective trigger functions. Mon. Wea. Rev., 124, 2438-2452, https://doi.org/ 10.1175/1520-0493(1996)124<2438:AGFFCT>2.0.CO;2.

Shige, S., Y. N. Takayabu, W.-K. Tao, and D. E. Johnson, 2004: Spectral retrieval of latent heating profiles from TRMM PR data. Part I: Development of a model-based algorithm. J. Appl. Meteor., 43, 1095-1113, https://doi.org/10.1175/15200450(2004)043<1095:SROLHP>2.0.CO;2.

,,--- , and C.-L. Shie, 2007: Spectral retrieval of latent heating profiles from TRMM PR data. Part II: Algorithm improvement and heating estimates over tropical ocean regions. J. Appl. Meteor. Climatol., 46, 1098-1124, https:// doi.org/10.1175/JAM2510.1.

$\longrightarrow, \ldots$, and — 2008: Spectral retrieval of latent heating profiles from TRMM PR data. Part III: Estimating apparent moisture sink profiles over tropical oceans. J. Appl. Meteor. Climatol., 47, 620-640, https://doi.org/10.1175/2007JAMC1738.1.

- _ - S. Kida, W.-K. Tao, X. Zeng, C. Yokoyama, and T. L'Ecuyer, 2009: Spectral retrieval of latent heating profiles from TRMM PR data. Part IV: Comparisons of lookup tables from two- and three-dimensional cloud-resolving model simulations. J. Climate, 22, 5577-5594, https://doi.org/10.1175/ 2009JCLI2919.1.

Song, F., and T. Zhou, 2014a: Interannual variability of East Asian summer monsoon simulated by CMIP3 and CMIP5 AGCMs: Skill dependence on Indian Ocean-western Pacific anticyclone teleconnection. J. Climate, 27, 1679-1697, https://doi.org/10.1175/JCLI-D-13-00248.1.

— and _ 2014b: The climatology and interannual variability of East Asian summer monsoon in CMIP5 coupled models: Does air-sea coupling improve the simulations? J. Climate, 27, 8761-8777, https://doi.org/10.1175/JCLI-D-14-00396.1.

Sperber, K. R., and H. Annamalai, 2014: The use of fractional accumulated precipitation for the evaluation of the annual cycle of monsoons. Climate Dyn., 43, 3219-3244, https:// doi.org/10.1007/s00382-014-2099-3.

_, - _ I.-S. Kang, A. Kitoh, A. Moise, A. Turner, B. Wang, and T. Zhou, 2013: The Asian summer monsoon: 
An intercomparison of CMIP5 vs. CMIP3 simulations of the late 20th century. Climate Dyn., 41, 2711-2744, https:// doi.org/10.1007/s00382-012-1607-6.

Takayabu, Y. N., S. Shige, W.-K. Tao, and N. Hirota, 2010: Shallow and deep latent heating modes over tropical oceans observed with TRMM PR spectral latent heating data. J. Climate, 23, 2030-2046, https://doi.org/10.1175/2009JCLI3110.1.

Tanaka, M., 1992: Intraseasonal oscillation and the onset and retreat dates of the summer monsoon over East, Southeast Asia and the western Pacific region using GMS high cloud amount data. J. Meteor. Soc. Japan, 70, 613-629, https://doi.org/ 10.2151/jmsj1965.70.1B_613.

Tao, S., L.-X. Chen, C.-P. Chang, and T. N. Krishnamurti, 1987: A review of recent research on the East Asian summer monsoon in China. Monsoon Meteorology, Oxford University Press, 60-92.

Tao, W.-K., and Coauthors, 2016: TRMM latent heating retrieval: Applications and comparisons with field campaigns and largescale analyses. Multiscale Convection-Coupled Systems in the Tropics: A Tribute to Dr. Michio Yanai, Meteor. Monogr., Vol. 56, Amer. Meteor. Soc., 2.1-2.34, https://doi.org/10.1175/ AMSMONOGRAPHS-D-15-0013.1.

Tsai, W.-M., and C.-M. Wu, 2017: The environment of aggregated deep convection. J. Adv. Model. Earth Syst., 9, 2061-2078, https://doi.org/10.1002/2017MS000967.

Wang, B., and Q. Ding, 2008: Global monsoon: Dominant mode of annual variation in the tropics. Dyn. Atmos. Oceans, 44, 165183, https://doi.org/10.1016/j.dynatmoce.2007.05.002.

_- LinHo, Y. Zhang, and M.-M. Lu, 2004: Definition of South China Sea monsoon onset and commencement of the East Asia summer monsoon. J. Climate, 17, 699-710, https:// doi.org/10.1175/2932.1.

_, Q. Ding, X. Fu, I.-S. Kang, K. Jin, J. Shukla, and F. DoblasReyes, 2005: Fundamental challenge in simulation and prediction of summer monsoon rainfall. Geophys. Res. Lett., 32, L15711, https://doi.org/10.1029/2005GL022734.

__ F. Huang, Z. Wu, J. Yang, X. Fu, and K. Kikuchi, 2009: Multiscale climate variability of the South China Sea monsoon: A review. Dyn. Atmos. Oceans, 47, 15-37, https://doi.org/ 10.1016/j.dynatmoce.2008.09.004.

_ , H.-J. Kim, K. Kikuchi, and A. Kitoh, 2011: Diagnostic metrics for evaluation of annual and diurnal cycles. Climate Dyn., 37, 941-955, https://doi.org/10.1007/s00382-010-0877-0.

Wang, J.-J., and L. D. Carey, 2005: The development and structure of an oceanic squall-line system during the South China Sea Monsoon Experiment. Mon. Wea. Rev., 133, 1544-1561, https://doi.org/10.1175/MWR2933.1.

Wang, Y.-C., H.-L. Pan, and H.-H. Hsu, 2015: Impacts of the triggering function of cumulus parameterization on warm-season diurnal rainfall cycles at the Atmospheric Radiation Measurement Southern Great Plains site. J. Geophys. Res. Atmos., 120 , 10 681-10 702, https://doi.org/10.1002/2015JD023337.

Wapler, K., and T. P. Lane, 2012: A case of offshore convective initiation by interacting land breezes near Darwin, Australia. Meteor. Atmos. Phys., 115, 123-137, https://doi.org/10.1007/ s00703-011-0180-6.

Webster, P. J., V. O. Magaña, T. N. Palmer, J. Shukla, R. A. Tomas, M. Yanai, and T. Yasunari, 1998: Monsoons: Processes, predictability, and the prospects for prediction. J. Geophys. Res., 103, 14 451-14 510, https://doi.org/10.1029/97JC02719.

Williams, K. D., and Coauthors, 2013: The Transpose-AMIP II Experiment and its application to the understanding of Southern Ocean cloud biases in climate models. J. Climate, 26, 3258-3274, https://doi.org/10.1175/JCLI-D-12-00429.1.
Williamson, D. L., 2013: The effect of time steps and time-scales on parametrization suites. Quart. J. Roy. Meteor. Soc., 139, 548560, https://doi.org/10.1002/qj.1992.

Wu, C.-H., and H.-H. Hsu, 2016: Role of the Indochina Peninsula narrow mountains in modulating the East Asian-western North Pacific summer monsoon. J. Climate, 29, 4445-4459, https://doi.org/10.1175/JCLI-D-15-0594.1.

, N. Freychet, C.-A. Chen, and H.-H. Hsu, 2017: East Asian presummer precipitation in the CMIP5 at high versus low horizontal resolution. Int. J. Climatol., 37, 4158-4170, https:// doi.org/10.1002/joc.5055.

_ M.-D. Chou, and Y.-H. Fong, 2018: Impact of the Himalayas on the Meiyu-Baiu migration. Climate Dyn., 50, 1307-1319, https://doi.org/10.1007/s00382-017-3686-x.

Wu, C.-M., B. Stevens, and A. Arakawa, 2009: What controls the transition from shallow to deep convection? J. Atmos. Sci., 66, 1793-1806, https://doi.org/10.1175/2008JAS2945.1.

Xie, S., and M. Zhang, 2000: Impact of the convection triggering function on single-column model simulations. J. Geophys. Res., 105, 14983 14 996, https://doi.org/10.1029/2000JD900170.

$\longrightarrow,-$ J J. S. Boyle, R. T. Cederwall, G. L. Potter, and W. Lin, 2004: Impact of a revised convective triggering mechanism on Community Atmosphere Model, version 2, simulations: Results from short-range weather forecasts. J. Geophys. Res., 109, D14102, https://doi.org/10.1029/2004JD004692.

- , H. Ma, J.S. Boyle, S.A. Klein, and Y. Zhang, 2012: On the correspondence between short- and long-time-scale systematic errors in CAM4/CAM5 for the Year of Tropical Convection. J. Climate, 25, 7937-7955, https://doi.org/10.1175/ JCLI-D-12-00134.1.

Xu, W., and S. A. Rutledge, 2018: Convective variability associated with the boreal summer intraseasonal oscillation in the South China Sea region. J. Climate, 31, 7363-7383, https://doi.org/ 10.1175/JCLI-D-18-0091.1.

Yanai, M., S. Esbensen, and J.-H. Chu, 1973: Determination of bulk properties of tropical cloud clusters from large-scale heat and moisture budgets. J. Atmos. Sci., 30, 611-627, https://doi.org/10.1175/ 1520-0469(1973)030<0611:DOBPOT>2.0.CO;2.

Yokoi, S., S. Mori, M. Katsumata, B. Geng, K. Yasunaga, F. Syamsudin, Nurhayati, and K. Yoneyama, 2017: Diurnal cycle of precipitation observed in the western coastal area of Sumatra Island: Offshore preconditioning by gravity waves. Mon. Wea. Rev., 145, 3745-3761, https://doi.org/10.1175/ MWR-D-16-0468.1.

Zhang, G. J., and N. A. McFarlane, 1995: Sensitivity of climate simulations to the parameterization of cumulus convection in the Canadian Climate Centre General Circulation Model. Atmos.-Ocean, 33, 407-446, https:// doi.org/10.1080/07055900.1995.9649539.

Zhou, T., B. Wu, and B. Wang, 2009: How well do atmospheric general circulation models capture the leading modes of the interannual variability of the Asian-Australian monsoon? J. Climate, 22, 1159-1173, https://doi.org/10.1175/ 2008JCLI2245.1.

— , and Coauthors, 2016: GMMIP (v1.0) contribution to CMIP6: Global Monsoons Model Inter-Comparison Project. Geosci. Model Dev., 9, 3589-3604, https://doi.org/10.5194/gmd-9-35892016.

Zhou, Y. P., and Coauthors, 2007: Use of high-resolution satellite observations to evaluate cloud and precipitation statistics from cloud-resolving model simulations. Part I: South China Sea Monsoon Experiment. J. Atmos. Sci., 64, 4309-4329, https://doi.org/10.1175/2007JAS2281.1. 